\title{
State-of-the-art polymeric nanoparticles as promising therapeutic tools against human bacterial infections
}

\author{
Amanda Cano ${ }^{1,2,3^{*}}$, Miren Ettcheto ${ }^{3,4,5}$, Marta Espina ${ }^{1,2}$, Ana López-Machado 1,2, Yolanda Cajal1,2, \\ Francesc Rabanal ${ }^{6}$, Elena Sánchez-López ${ }^{1,2,3}$, Antonio Camins ${ }^{3,4}$, Maria Luisa García ${ }^{1,2,3+}$ and Eliana B. Souto ${ }^{7,8+}$
}

\begin{abstract}
Infectious diseases kill over 17 million people a year, among which bacterial infections stand out. From all the bacterial infections, tuberculosis, diarrhoea, meningitis, pneumonia, sexual transmission diseases and nosocomial infections are the most severe bacterial infections, which affect millions of people worldwide. Moreover, the indiscriminate use of antibiotic drugs in the last decades has triggered an increasing multiple resistance towards these drugs, which represent a serious global socioeconomic and public health risk. It is estimated that 33,000 and 35,000 people die yearly in Europe and the United States, respectively, as a direct result of antimicrobial resistance. For all these reasons, there is an emerging need to find novel alternatives to overcome these issues and reduced the morbidity and mortality associated to bacterial infectious diseases. In that sense, nanotechnological approaches, especially smart polymeric nanoparticles, has wrought a revolution in this field, providing an innovative therapeutic alternative able to improve the limitations encountered in available treatments and capable to be effective by theirselves. In this review, we examine the current status of most dangerous human infections, together with an in-depth discussion of the role of nanomedicine to overcome the current disadvantages, and specifically the most recent and innovative studies involving polymeric nanoparticles against most common bacterial infections of the human body.
\end{abstract}

Keywords: Bacterial infections, Infectious diseases, Polymeric nanoparticles, Nanomedicine, Nanotechnology

\section{Highlights}

- Infectious diseases kill over 17 million people a year, and pose a huge health and socioeconomic burden worldwide.

- Tuberculosis, diarrhoea, meningitis, pneumonia, sexual transmission diseases and nosocomial infections are the most severe bacterial infections, which affect millions of people worldwide.

*Correspondence: acanofernandez@ub.edu

†Maria Luisa García and Eliana B. Souto senior co-authors

'Department of Pharmacy, Pharmaceutical Technology and Physical

Chemistry, Faculty of Pharmacy and Food Sciences, University

of Barcelona, Av Joan XXIII, 27-31, 08017 Barcelona, Spain

Full list of author information is available at the end of the article
- Antibiotic multiple resistance is exponentially increasing due to the indiscriminate use of antibiotic drugs.

- It is estimated that 33,000 and 35,000 people die yearly in Europe and the United States, respectively, as a direct result of antimicrobial resistance.

- Nanotechnological strategies have emerged in the recent years as a promising alternative to solve these problems and improve available antibiotics effectiveness.

- It is well reported that polymers possess by themselves antibiotic effect.

- State-of-the-art polymeric nanoparticles possess optimal physicochemical characteristics to become a therapeutic revolution against bacterial infections. 


\section{Introduction}

Infectious diseases kill over 17 million people a year over the world [1]. Bacterial infections have a large impact on public health. Drug-resistant bacteria, viruses, parasites and fungi cause 700,000 deaths every year worldwide [2]. The latest Global Health Study undertaken by the World Health Organization (WHO) dated from 2016, estimated that infectious and parasitic diseases represent $9.7 \%$ from the whole deaths worldwide. In this ranking, tuberculosis has been placed as the first cause of death among bacterial infections (2.3\% of global deaths), followed by diarrhoeal bacterial diseases (2\%), meningitis $(0.5 \%)$, bacterial sexual transmission disease (syphilis, chlamydia and gonorrhoea, $0.2 \%$ ) and encephalitis $(0.2 \%)$ [1]. Similarly, the latest reports of the Global Burden of Diseases consortium highlighted that, in 2016, infectious diarrhoea was the eighth leading cause of death among all ages and the fifth leading cause of death among children, being Shigella and enterotoxigenic Escherichia coli the most frequent and mortal bacteria [3, 4]; incident cases of meningitis globally increased 2.82 million in 2016, being the Pneumococcus the largest cause of years of life lived with disability (YLDs) [5]; the number of tuberculosis deaths was 1.21 million among HIV-negative individuals and 0.24 million among HIV-positive individuals [6]. Furthermore, in 2017, 11.0 million sepsis-related deaths were reported worldwide [7].

Not surprisingly, these data are significantly higher than the global computation in developing countries, since the lack of universal health systems, public health problems and access to potable drinking water, together with the limited financial resources, aggravate the situation of these patients $[1,4]$. On the other hand, the indiscriminate use of antibiotic drugs in recent decades worldwide has generated a global public health problem due to the emergence of multiple resistance against antibiotics by a high number of microorganisms [8]. It is predicted that, by 2050, multidrug resistant (MDR) bacteria will cause up to 10 million deaths annually, with a burden cost in the global economy reaching US\$100 trillion [2].

Although the human body lives together with its own microbiota in an advantageous symbiosis, there are many bacteria pathogens capable to infect and colonize the human body and cause serious diseases (Table 1). Bacteria can be transmitted to humans through food, water, air, or living vectors. All of the human organs are susceptible to be infected by bacteria, but each species has a predilection for certain organs, and some organs are more sensitive to suffer bacterial infection (Fig. 1) [9]. "ESKAPE" bacteria is one of the groups of bacteria that are of greatest concern in the health environment due to several reasons. ESKAPE is an acronym encompassing the names of six most dangerous bacterial human pathogens (Enterococcus faecium, Staphylococcus aureus, Klebsiella pneumoniae, Acinetobacter baumannii, Pseudomonas aeruginosa, and Enterobacter species) commonly associated with a high antimicrobial resistance, which are responsible of the majority of nosocomial infections. Curiously, this acronym also references to the ability of these microorganism to escape the effects of commonly used antibiotics through evolutionarily developed mechanisms [10].

Other of the most dangerous bacteria for humans are Neisseria meningitides and Vibrio cholera, both belonging to the proteobacteria phylum $N$. meningitides is an exclusively human pathogen, causing bacterial meningitis in children and young adults, which finally lead to the death of the ten percent of the cases [11]. People with confirmed $N$. meningitidis infection should be hospitalized immediately for antibiotic treatment due to the severity of the symptoms [12]. On its behalf, $V$. cholerae causes cholera in humans. This pathogen is usually transmitted through the ingestion of contaminated food or water [13]. V. cholerae infection is limited to the intestinal tract, where disease symptoms are primarily caused by its toxins. It is mostly found in developing countries, since the lack of access to drinking water promotes its expansion, becoming an endemic disease in these regions [14].

Clostridium difficile is the most important cause of pseudomembranous colitis, an infection of the colon, often secondary to the eradication of the saprophyte microbiota. Antibiotics, especially broad-spectrum antibiotics, cause an imbalance of the intestinal flora, leading to an overpopulation of $C$. difficile, which in turn promotes the pseudomembranous colitis [15]. Due to the severity of this infection, monoclonal antibodies and drugs such Surotomycin, Rifamixin or Cadazolid are being studied in clinical trials as promising alternatives to currently available treatments [16].

Mycobacterium tuberculosis is responsible for the largest number of tuberculosis cases and the first cause of death in the world due to bacterial infection. Humans are the only known reservoirs of $M$. tuberculosis, which causes severe infection in lungs, but also spreading to other organs [17]. Importantly, the unusual structure and chemical composition of the mycobacterial cell wall deeply difficult the efficacy of the treatments, since drug penetration is almost impossible. [18].

Finally, Chlamydia trachomatis is an obligate intracellular bacterium that can replicate only within a host human cell [19]. C. trachomatis causes trachoma, oculogenital infections, nongonococcal urethritis and pneumonia. Moreover, $C$. trachomatis is the most common infectious cause of blindness and the most common sexually transmitted bacterium [20]. 
Table 1 Characteristics of most dangerous human infectious bacteria

\begin{tabular}{|c|c|c|c|c|c|c|c|}
\hline Bacteria specie & Phylum & Order & Gram \pm & Medium & Disease & Treatment & Morphology \\
\hline $\begin{array}{l}\text { Enterococcus } \\
\text { faecium }\end{array}$ & Firmicutes & Lactobacillales & + & Aerobic/Anaerobic & $\begin{array}{l}\text { Meningitis } \\
\text { Endocarditis } \\
\text { Nosocomial inf }\end{array}$ & $\begin{array}{l}\text { Linezolid } \\
\text { Daptomycin } \\
\text { Tigecycline } \\
\text { Streptogramins } \\
\text { Sultamicillin }\end{array}$ & \\
\hline $\begin{array}{l}\text { Staphylococcus } \\
\text { aureus }\end{array}$ & Firmicutes & Bacillales & + & Aerobic/Anaerobic & $\begin{array}{l}\text { Skin inf } \\
\text { Respiratory inf } \\
\text { Nosocomial inf }\end{array}$ & $\begin{array}{l}\text { Penicillin } \\
\text { Oxacillin } \\
\text { Flucloxacillin } \\
\text { Kanamycin } \\
\text { Gentamicin } \\
\text { Streptomycin }\end{array}$ & \\
\hline $\begin{array}{c}\text { Pseudomonas } \\
\text { aeruginosa }\end{array}$ & Proteobacteria & Pseudomonadales & - & Aerobic/Anaerobic* & $\begin{array}{l}\text { Sepsis syndromes } \\
\text { Pneumonia } \\
\text { Nosocomial inf }\end{array}$ & $\begin{array}{l}\text { Aminoglycosides } \\
\text { Quinolones } \\
\text { Cephalosporins } \\
\text { Carboxypenicillins } \\
\text { Ureidopenicillins } \\
\text { Carbapenems } \\
\text { Polymyxins } \\
\text { Monobactams }\end{array}$ & \\
\hline $\begin{array}{l}\text { Klebsiella pneumo- } \\
\text { niae }\end{array}$ & Proteobacteria & Enterobacterales & - & Anaerobic ${ }^{¥}$ & Nosocomial inf & $\begin{array}{l}\text { Aminoglycosides } \\
\text { Cephalosporins }\end{array}$ & \\
\hline $\begin{array}{c}\text { Acinetobacter } \\
\text { baumannii }\end{array}$ & Proteobacteria & Pseudomonadales & - & Aerobic & $\begin{array}{l}\text { Nosocomial inf } \\
\text { Meningitis }\end{array}$ & $\begin{array}{l}\text { Imipenem } \\
\text { Meropenem } \\
\text { Polymyxins }\end{array}$ & \\
\hline Enterobacter spp. & Proteobacteria & Enterobacterales & - & Anaerobic & $\begin{array}{l}\text { Nosocomial inf } \\
\text { Urinary inf } \\
\text { Respiratory inf }\end{array}$ & $\begin{array}{l}\text { Cefepime } \\
\text { Imipenem } \\
\text { Aminoglycosides } \\
\text { Quinolones } \\
\text { Polymyxins }\end{array}$ & \\
\hline $\begin{array}{l}\text { Mycobacterium } \\
\text { tuberculosis }\end{array}$ & Actinobacteria & Actinomycetales & \pm & Aerobic & Tuberculosis & $\begin{array}{l}\text { Isoniazid } \\
\text { Rifampin } \\
\text { Pyrazinamide } \\
\text { ethambutol } \\
\text { Bedaquiline }\end{array}$ & \\
\hline Clostridium difficile & Firmicutes & Clostridiales & + & Aerobic & $\begin{array}{l}\text { Diarrhea } \\
\text { Intestinal Inflam- } \\
\text { mation }\end{array}$ & $\begin{array}{l}\text { Stop antibiotic } \\
\text { therapy } \\
\text { Vancomycin } \\
\text { Metronidazole } \\
\text { Fidaxomicin }\end{array}$ & \\
\hline $\begin{array}{l}\text { Chlamydia tra- } \\
\text { chomatis }\end{array}$ & Chlamydiae & Chlamydiales & - & Aerobic & $\begin{array}{l}\text { trachoma } \\
\text { lymphogranuloma } \\
\text { venereum } \\
\text { nongonococcal } \\
\text { urethritis cervicitis } \\
\text { salpingitis } \\
\text { pelvic inflammatory } \\
\text { disease } \\
\text { blindness }\end{array}$ & $\begin{array}{l}\text { Tetracycline } \\
\text { Doxycycline } \\
\text { Azithromycin } \\
\text { erythromycin } \\
\text { Ofloxacin }\end{array}$ & \\
\hline $\begin{array}{l}\text { Neisseria menin- } \\
\text { gitidis }\end{array}$ & Proteobacteria & Neisseriales & - & Aerobic & Meningitis & $\begin{array}{l}\text { Cephalosporins } \\
\text { Penicillin G } \\
\text { Chloramphenicol } \\
\text { Corticosteroids }\end{array}$ & \\
\hline
\end{tabular}


Table 1 (continued)

\begin{tabular}{lllllll}
\hline Bacteria specie & Phylum & Order & Gram \pm & Medium & Disease & Treatment \\
\hline Vibrio cholerae & Proteobacteria & Vibrionaceae & - & Anaerobic $^{*}$ & Cholera & $\begin{array}{c}\text { Hydration, glucose } \\
\text { and electrolytes } \\
\text { Tetracycline chlo- } \\
\text { ramphenicol }\end{array}$ \\
& & & & & \\
& & & & \\
\end{tabular}

*Commonly aerobic/less common facultative anaerobic

¥ Facultative anaerobic

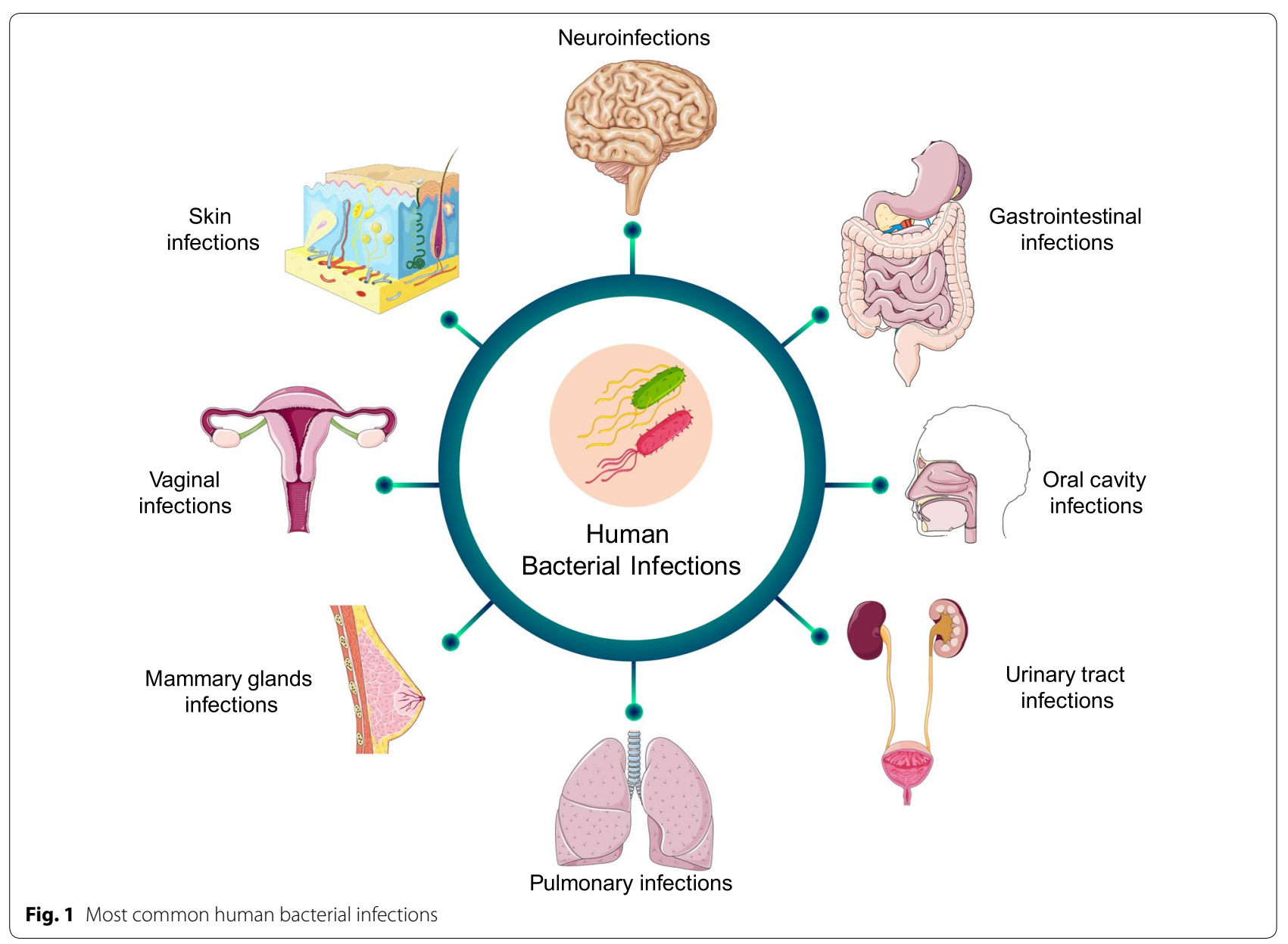

All these facts together highlight the global importance and severity of the antibiotic resistance issue, which arises the need to find new alternatives for these patients. In this sense, nanomedicine has become in the last decades in a revolutionary therapeutic tool [21]. The ability of controlled drug delivery systems to carry inside different antibiotics, enhance their solubility, target them to a specific organ and improve its penetration has opened a window of opportunities to overcome the disadvantages of the current antibiotic treatments and novel potential molecules [21]. Moreover, the possibility of accumulate the drug at the site of infection for a longer time, as well as avoiding the escape mechanisms of bacteria generate a great interest among the scientific community [21].

Specifically, polymeric nanoparticles (NPs) have emerged as a promising alternative mainly due to the polymeric structure. Polymeric materials have exhibited to possess antibiotic effects [22]. Among their several effects, it is highlighted their ability to accumulate onto the cell membranes, which finally promote the destruction of the entire bacteria cell. These polymer effects together with antibacterial properties of loaded drugs 
confers to these nanosystems many advantages as a multitarget approach against different infections [22]. Thus, in this review we deeply investigate and describe the main advantages of nanomedicine, specifically the stateof-the-art polymeric NPs, against most common human bacterial infections, as well as recent advances in novel drugs-loaded polymeric NPs as antibiotic therapies.

\section{Nanoparticles to improve antibacterial therapies}

In the 1940s, penicinils promoted a revolution in the therapy of the twentieth century, significantly contributing to the control of infectious diseases, which were the leading cause of human mortality so far [23]. Due to this therapeutic success, over the last 50 decades, there was an indiscriminate use of these drugs, which led to several antibiotic resistances by many bacterial species, which implies a serious public health risk. Spontaneous modifications in the genetic material of these microorganisms improved their adaptation to the environment and the development of molecular mechanisms that limit the action of these agents, such as the production of degrading enzymes or the increase in their efflux pumps [10]. It is estimated that 33,000 and 35,000 people die yearly in Europe and the United States, respectively, as a direct result of antimicrobial resistance [24, 25].

For these reasons, the is a current need to improve the biopharmaceutical properties of existing compounds and also to find new, more effective antibacterial agents. Recent advances in nanotechnology, particularly the design of novel nanoparticles (NPs) as controlled drug delivery systems, have supposed a promising alternative impact in the general medicine, and specifically in the antimicrobial therapy [26]. NPs, controlled drug delivery systems with a diameter of $1-1000 \mathrm{~nm}$ and polymeric core, may offer remarkable improvements in the biopharmaceutical properties of antibacterial agents. Notably, they can provide an enhancement of drug solubility, modulation of drug release and delivery, promotion of stealth for immune evasion, targeting of antibacterial molecules to desired organs and tissues and increase the retention time in-situ, as well as the simultaneous delivery of multiple drugs [27]. Such unique advantages allow these systems to improve the therapeutic index of drug payloads when compared with free drug counterparts, perform an efficient focused therapy at the site of infection, increasing the penetration of loaded molecules through the bacteria cell wall, thus opening a window against antibacterial resistance [28].

Different strategies by which NPs can improve antibacterial therapy efficacy have already been described (Fig. 2) [29, 30]. The most important strategy is the antibiotic localization to the pathogen cell. This allows to reduce the therapeutic doses of the drugs, maintaining their efficacy and reducing the adverse effects [26]. The modulation of drug-pathogen interaction to overcome antibiotic resistance is another of the most effective strategies. For example, liposomes have the capacity of fusing themselves directly with bacterial membranes. This leads to a burst-release of high dose of loaded antibiotics into the bacteria, overwhelming the efflux pumps and overcoming this bacterial resistance mechanism [26]. NPs enable free drug "anti-virulence" therapy. In comparison to traditional antibiotics, nanoparticles are less likely to develop drug resistance, since there is no bactericidal effect, but rather promoted physical and non-specific structural disruption of bacterial membranes, that ultimately led to an increased permeation and bacterial cell death. This process is less likely to elicit resistance development [31]. Furthermore, some anti-virulence platforms include monoclonal antibodies, anti-sera, small-molecule inhibitors or small polymers [26].

\section{Nanoparticles for bacteria recognition}

The recognition of bacteria by detecting specific elements with NPs, which would act as biosensors, is one of the most innovative and emerging strategies to rapidly recognise and treat an infection. The large surface area of nanoparticles allows, not only the increase of the contact between loaded drug and bacterial film, but also a more efficient recruiting of bacterial antigens. Thus, different strategies have been explored in that sense.

\section{Antibody-based strategies}

NPs surface modification with specific antibodies comprises the most commonly used bio-recognition approach to capture pathogens cells due to their versatility and their high affinity to different bacteria elements. Polyclonal, monoclonal, and engineered antibody fragments are the antibodies employed in immunology-based assays in bacterial infections [32].

\section{Aptamer-based strategies}

Aptamers are single stranded nucleic acids which offer many advantages over antibody-based strategies. These advantages include their chemical stability, low-cost, and large-scale synthesis process. Moreover, due to their small size (between 3 and $5 \mathrm{~nm}$ ), aptamers exhibit a remarkable binding affinity against different bacterial cell elements, thus resulting in a significant reduction of the detection limit [32]. Systematic Evolution of Ligands by Exponential enrichment (SELEX) technique is commonly used in the design of aptamers for a huge variety of bacteria [33]. This technique is based on the identification and amplification of an effective aptamer sequence, 


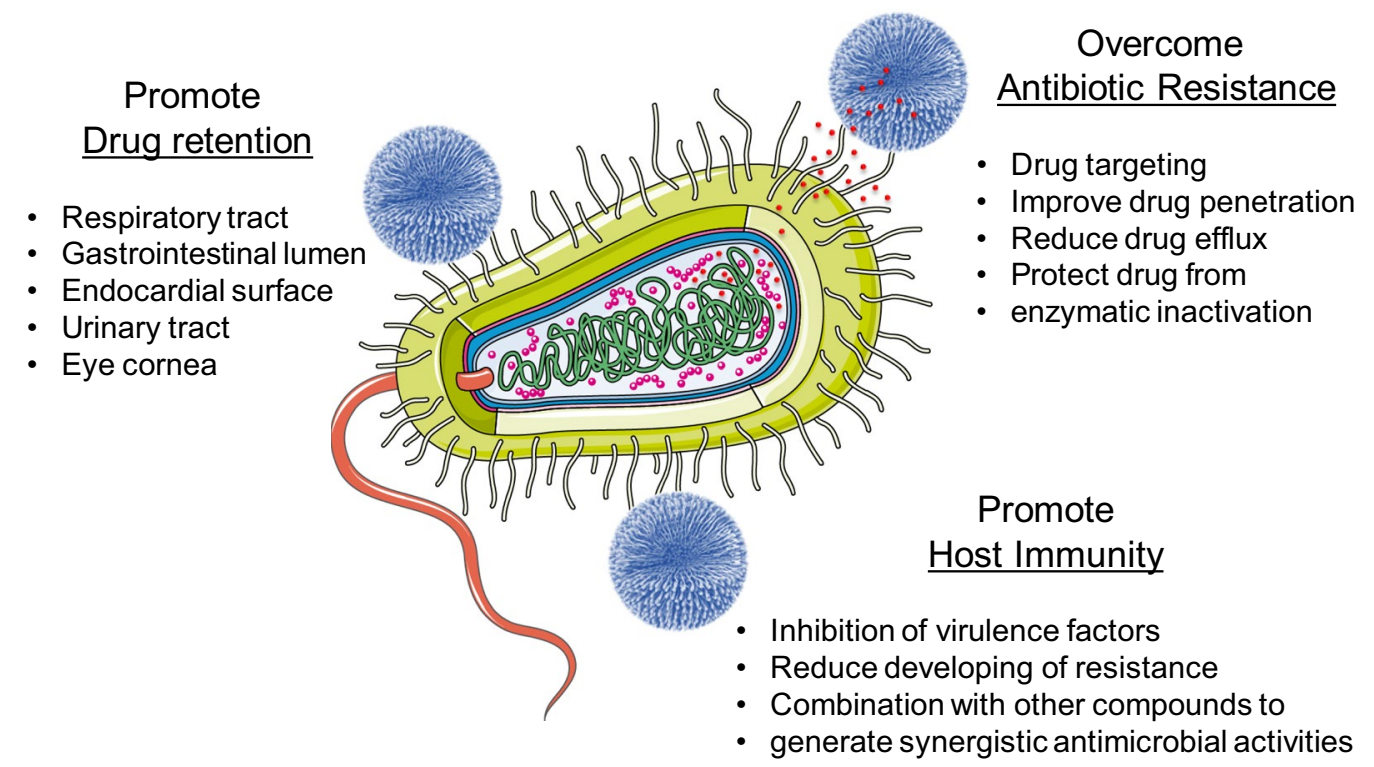

Fig. 2 Main improvements brought by nanoparticles for the antibacterial therapy

which will be conjugated with $-\mathrm{COOH}-\mathrm{SH}$ and $-\mathrm{NH}_{2}$ groups and immobilize onto NPs surface.

\section{Electrostatic interaction-based strategies}

Positively charged nanoparticles can bind to negatively charged protein surfaces, such bacteria cell membrane, through electrostatic interactions. Several type of nanoparticles, such as chitosan nanoparticles, gold nanoparticles, graphene oxide nanoparticles or carbon nanotubes, have been reported to interact with bacteria elements, such enzymes, and inhibiting their activities. Moreover, due to the reversible characteristic of electrostatic interactions, this recognition's process can be used as an indirect indicator of bacterial cell concentration [32].

\section{Bacteriophage-based strategies}

Bacteriophages are basic bacteria-infecting viruses comprised by a protein capsid evolving of nucleic acids and tail fibres. These tail fibres are used as recognition elements, which can specifically bind to bacterial surface receptors. The most important characteristic of bacteriophages is their ability to distinguish inactive versus viable host cells, since they can only replicate within alive bacterial cells [34]. In addition, their synthesis and purification processes are relatively easy and inexpensive, together with their medium size (ca. $100 \mathrm{~nm}$ ), making them a promising biosensoring platform to be combined with NPs for bacteria detection [32].

\section{Nanoparticles to protect and improve drug effectiveness} The targeting and recognition of specific bacterial structures is not the only strategy to improve antibacterial therapies using nanotechnology. The encapsulation of available antibiotics to improve their properties, as well as new molecules with bactericidal potential, is one of the main objectives of NPs. Likewise, the preservation of the physicochemical properties of encapsulated compounds, as well as an increase in their stability throughout their storage and administration in vivo, are fundamental characteristics provided by nanocarriers that provide a guarantee of success in therapies.

Nitric oxide (NO) is one of the compounds that as raised much interest in the last years because of its antibacterial properties. NO has been recently identified as a key regulator of bacterial biofilm dispersion, but its reduced water solubility, short half-life and extremely reactiveness involve a challenge to exploit its therapeutic potential [35]. In that sense, Duong et al. developed two different NO-loaded controlled drug delivery systems: (i) functional gold NPs and (ii) core cross-linked star polymers to improve the stability of NO during the storage and perform a controlled release [36, 37]. Both systems were exposed to Pseudomonas biofilms and NO dispersant activity was evaluated. In both cases, nanosystems increased NO stability, showed a slow and controlled delivery of NO, and exhibited a great efficacy in preventing both cell attachment and biofilm formation, with no signals of toxic mechanisms. 
Similarly, another interesting study explored the co-encapsulation of $\mathrm{NO}$ and gentamicin in polyoligo(ethyleneglycol) methyl ether methacrylate NPs as a potential antibacterial tool against bacterial biofilm and planktonic cultures [38]. Gentamicin is an aminoglucoside widely used in several bacterial infections, but with serious ear and kidney toxicity. In this study, authors founded that developed NPs were able to perform a controlled release both agents simultaneously, and exhibited synergistic effects. The viability of planktonic cultures and Pseudomonas biofilm was reduced by more than $95 \%$ and $90 \%$, respectively, whereas free drugs treatments alone resulted in less than $20 \%$ of decrease in biofilm viability.

Another antibacterial strategy exploited with nanotechnology is the increase of the temperature in the infected area. It has been described that this increase can induce a detachment of bacteria biofilms and reduction of biofilm biomass. In that sense, Nguyen et al. developed iron oxide NPs to disrupt the bacterial biofilm through a NPs-mediated hyperthermia [39]. Upon an exposure to a magnetic field, developed NPs induced the detachment of biofilm cells and reduced by 2-log the number of colony forming units (CFUs) in both biofilm and planktonic phases in combination with gentamicin treatment.

All these findings together may find broad applications across a range of clinical and industrial settings related to bacterial infections management.

\section{Polymers as a new generation of antibacterial agents}

In the last decade, mainly due to the rise of antibacterial drugs resistance, there has been an increase in the search of new compounds able to act against these microorganisms. In this context, antimicrobial polymers (AMP) have emerged as a promising alternative in this field [40]. As described above, polymers by themselves have shown to be promising therapeutic agents against multiple antibiotic resistant bacteria. These materials were designed to mimic the chemical structure of antimicrobial peptides, which are part of the human immune system and are responsible of the protection of the host against different pathogen [41]. Hydrophobicity and cationic charge have been described as the most important properties of these materials to possess antibacterial activity. These characteristics lead to an accumulation of these polymers onto the cell membranes, creating pores on the bacterial structure, thus finally killing them [42].

The composition and distribution of the monomers in the polymer chain have been also described to possess a significant impact in the antibacterial activity. Some studies have pointed out that the incorporation of hydrophobic and amine groups in the terminal positions of the polymer chain allows to vary its hydrophobicity and lead to adjust the extent of bacterium membrane disruption, which in turn governs the antimicrobial activity $[43,44]$. Furthermore, it has been also described that the incorporation of oligoethylene glycol in the polymeric structure prevent the complexation of AMP with proteins, which significantly contributes to maintain antimicrobial efficacy [44]. Likewise, polymer architecture also influences in its bactericidal effect. It has been described that polymer longer chains are more bacteriostatic against Gramnegative bacteria, whereas polymer shorter chains have less haemocompatibility. Moreover, hyperbranched polymeric structures possess similar antimicrobial activity compared to the short linear random copolymers with no hemagglutination [45].

Due to their inhering chemical structure, AMP can either promote antibacterial effect or serve as matrix to improve the efficacy of loaded antibiotics [22]. Synergistic effect between AMP and antibiotics have been described by several authors. Thus, Namivandi-Zangeneh et al. recently developed an antimicrobial platform composed by a potent synthetic AMP (oligoethylene glycol, ethylhexyl, and primary amine groups) and two antibiotics, colistin and doxycycline [46]. This study reveals the improvement.

of the bacteriostatic efficacy of both AMP and antibiotics when administered together. Moreover, this synergistic combination reduces the rate of resistance development compared to free compounds alone. Similarly, authors recently developed another platform where this AMP was combined with essential oils, carvacrol and eugenol [47]. Essential oils are natural antimicrobial agents produced by many plants. As it was expected, co-administration of these compounds significantly improves the efficacy against $P$. aeruginosa biofilms compared to free compounds. In this case, the synergistic bactericidal activity was attributed to the targeted delivery of carvacrol and eugenol, driven by the electrostatic interaction between positively polymer and negatively charged bacteria.

Ultimately, the versatility in the design of polymers has allowed to exploit all these advantages and obtain different polymeric structures with antimicrobial activity.

\section{Polymers mimicking natural peptides}

Natural peptides are commonly produced as an innate immune response against bacterial infections [22, 48]. The mechanism of action use to be non-receptor dependent and use to involve an interruption of internal cellular function [49, 50]. However, the clinical application of these peptides possesses several limitations because of their potential toxicity to the host, reduced halflife caused by protein binding, and susceptibility to 
degradation by host proteases [22]. To overcome these disadvantages, in the last years, a variety of polymers have been designed to simulate these natural peptides. Thus, many studies have described synthetic AMP mimicking peptides against most common human bacteria, such S. aureus, E. faecium or P. aeruginosa [22]. These synthetic AMP, such brilacidin or idolidicin variants, can act as bacteriostatic or bactericidal compounds with a reduced toxicity to the host, some of them even reaching phase II of clinical trials [51].

\section{Polymers enclosing phosphor- and sulfo- derivatives}

Other option of polymer strategy against bacteria are polysulphonium and polyphosphonium. Their mechanism of action is similar to those polymers which enclose quaternary ammonium in their structure, inducing a bacteria cell wall damage leading to their death [22]. These kind of matrices have been restricted to alkyl and aryl derivatives, which exhibit both hydrophobic and hydrophilic domains, a required feature to possess antimicrobial activity [52].

\section{Phenol and benzoic derivative polymers}

Aromatic compounds, such as benzoic acid or phenol group, have been described to possess antimicrobial properties, and their incorporation in the synthesis of novel polymers grants them the desired antimicrobial activity. Their mechanism of action is also related to the bacteria cell membrane breakdown, and are commonly used as environmental antibacterial agents. Thus, a few decades ago, some authors already explored the synthesis of vinyl polymers containing benzoic or phenol residues as terminal groups to evaluate their effectiveness against $S$. aureus and $P$. aeruginosa, demonstrating their efficacy against this pathogens [53].

\section{Halogen-derivatives enclosing polymers}

Antimicrobial properties of halogens are a well described mechanism that has been used in the design of most common antimicrobial agents, such chloramphenicol or vancomycin (which contain chlorine), or fluoroquinolones (which contains fluorine) [54]. Polymers containing halogens combine the antimicrobial properties of both structures, thus leading to an improvement of therapeutic efficacy. Some examples of this strategy are Quaterfluo ${ }^{\circledR}$, a polymeric fluorine containing antimicrobial surfactants, cationic fluorinated polymer emulsions, polymers contain $\mathrm{N}$-halamines, and halogenated polymers containing antimicrobials agents, such as ciprofloxacin [52, 55-57]. In the latter case, authors demonstrated that the incorporation of ciprofloxacin into the polymeric acidic matrix of amorphous solid dispersions, such Carbopol or Eudragit L100, improved the solubility of ciprofloxacin both in water and in simulated intestinal fluid. Moreover, these formulations improve the minimal inhibitory concentration of ciprofloxacin in S. aureus, $E$. coli, K. pneumoniae and P. aeruginosa cultures [56].

\section{Amphiphilic antibacterial polymers}

It has been demonstrated that polymer structures as well as their physicochemical properties, such as their molecular arrangement, molecular weight or ratio of amphiphilic composition, are the most important determinants of these materials which significantly compromise their selectivity and antimicrobial potency [22]. The ideal amphiphilic antibacterial polymer should possess a low molecular weight and low-level of lipophilicity, harbouring a cationic arm to incur adequate antibacterial activity with a minimum haemolysis activity towards red blood cells [58]. Some studies have demonstrated that AMPmimicking polyurethanes, with a lower hydrophobic regions and higher cationic strength, show higher bactericidal effect against $E$. coli with a lower haemolysis grade [59]. Likewise, degradable properties of AMP are instrumental for their antibacterial potency. Thus, changes on amine functionality and monomer composition of AMP to control their degradation rate could enhance the lifespan of the antimicrobial activity [60].

\section{Organometallic polymers}

Organometallic polymers are characterized by polymeric matrix containing metals bonded to at least one organic molecule carbon by coordination bonds, $\pi$-bonds or by $\sigma-/ \pi$-bonds to other elements [22]. One of the most used organometallic polymers are the silver-containing polymers, which have a higher antimicrobial activity in their solid form and have proven to be effective against most common bacterial infections, such $P$. aeruginosa, E. coli, $A$. niger or S. aureus [52]. Due to the environmental risk of metals compounds, the use of this kind of materials is compromised. However, a recent study carried out by Awad et al. explored the development of an eco-friendly silver-polystyrene nanocarrier using an extract of orange peel to reduce silver nitrate before creating the polymeric matrix [61]. Nevertheless, this kind of material requires further investigation to ensure their environmental safety.

\section{Recent polymeric nanoparticles against most common human bacterial infections Polymeric nanoparticles for pulmonary infections}

Respiratory infections, specifically lower tract lung infections, are a leading cause of morbidity and mortality worldwide. In 2016, lower respiratory infections (LRI) caused 2,377,697 deaths in people of all ages, being the adults older than 70 years the cohort of population with 
a higher risk. Streptococcus pneumoniae was the leading cause of LRI morbidity and mortality globally, contributing to more deaths than all other aetiologies combined [62]. According to WHO, pneumonia accounts for $15 \%$ of all deaths of children under 5 years old, killing 808 694 children in 2017 over the world [1]. Bacteria related to lung infections show a high resistance to antibacterial drugs, which has promoted a need to find new alternatives to solve this problem. Nanotechnology has shown to be a promising alternative to improve the success of therapy in these diseases (Table 2).

Among all bacterial infectious diseases associated with $P$. aeruginosa, lung infections are one of the most frequent, commonly as hospital-acquired pneumonia [63]. In that sense, an interesting study carried out by Schaefers et al. explored the development of polymeric NPs (PNPs) co-encapsulated with PopB, the P. aeruginosa type III secretion system protein, and its chaperon protein $\mathrm{PcrH}$ as a vaccine against IL-17 secretion by CD4 helper $\mathrm{T}$ cells in acute $P$. aeruginosa pneumonia [64]. This vaccine was administered intranasally in an in vivo mouse model. At the end of the study, authors found that PNPs-immunized mice exhibit 3-fourfold higher Th17 responses both in the lung and in the spleen compared to those immunized with free PopB/PcrH. Similarly, Deacon et al. explored the potential of PNPs against $P$. aeruginosa lung infections, in this case in comorbidity with cystic fibrosis. The aim of this study was the improvement of tobramycin bioavailability by its incorporation in PNPs. Tobramycin is an aminoglycoside with a limited effectiveness because of its inability to penetrate the thick DNA-rich mucus in the lungs, thus leading to low antibiotic exposure to resident bacteria. The evaluation of the nanocarrier effectiveness was performed in a fly in vivo model of $P$. aeruginosa infection [65]. Obtained results demonstrated that PNPs treatment double the survival rates, achieving $80 \%$, whereas free drug achieves only 40\%. When PNPs are functionalized with DNase, a significant DNA degradation in the mucus layer is observed, which is correlated with the enhanced PNPs penetration, thus finally leading to an increased anti-pseudomonal effect.

Tuberculosis infection is the deadliest disease caused by a single infectious agent, $M$. tuberculosis, ahead of malaria and HIV. According to WHO report, there were 10.4 million tuberculosis cases in 2016 and 1.7 million people dead worldwide [1]. Due to the high drug resistance that $M$. tuberculosis presents and the severity and extent of the pathology, a need has arisen to find new therapeutic alternatives against this pathogen. To overcome the limitations encountered in currently available treatments against $M$. tuberculosis lung infections, Coya et al. designed mannose functionalized PNPs to improve the response of innate immune human cells [66]. The ability of PNPs to promote inflammation processes could be useful against certain pathogens, but long-term inflammatory responses could be detrimental to the host. Because of that, authors chose the surface modification of PNPs with mannose in order to decrease their proinflammatory properties. Authors found that developed PNPs are efficiently internalized by human macrophages and profoundly remodel the response of $M$. tuberculosis-infected ones. Thus, grafting ligands at the surface of PNPs may be a promising strategy to modulate cell metabolism by immune response route and improve the efficacy of loaded molecules. Similarly, a recent study carried out by Malik et al. explored the encapsulation of the bivalent $\mathrm{H} 1$ antigen, a fusion of $M$. tuberculosis Ag85B and ESAT6 proteins, in PNPs to investigate its role in immunomodulation and protection in a mice model of M. tuberculosis lung infection [67]. In this case, developed PNPs are also efficiently internalized by the THP-1 human macrophages and the immunized mice exhibit a significant increase in the production of total serum IgGs. Moreover, in protection studies, immunized mice display significant reductions in lung and spleen bacterial load and prolonged survival.

Chlamydia psittaci infections are commonly transferred to humans via the inhalation of contaminated aerosols originating from excretions from infected animals. A recent study reported that $C$. psittaci lung infection may contribute to increase the risk of co-infection with other pathogens, including the flu virus, and has highlighted to be a one of the causes of communityacquired pneumonia $[68,69]$. Related to that, Li et al. developed a novel immunization strategy, simultaneous intranasal and intramuscular administration of PNPs coated with C. psittaci antigens to determine the different types of immune response and their protective role in an in vivo model of lung infection [70]. Obtained results showed that developed PNPs promote a strong immunity response by producing meaningfully high levels of IgG and secretory IgA antibodies. In addition, in vivo results exhibited that PNPs vaccine inhibits C. psittaci dissemination to different organs, as well as a reduction of bacterial loading and the degree of inflammation in the infected lungs.

\section{Polymeric nanoparticles for oral cavity infections}

Oral cavity infections, mainly caused by bacterium biofilm formation in different oral structures, involve a major public health and economic burdens worldwide. Oral biofilms are responsible for causing tooth decay and dental caries, and present a high prevalence in humans ( $>90 \%$ of adult population and (>30\% of schoolchildren over the world) [71]. Just in U.S., annual expenditures 


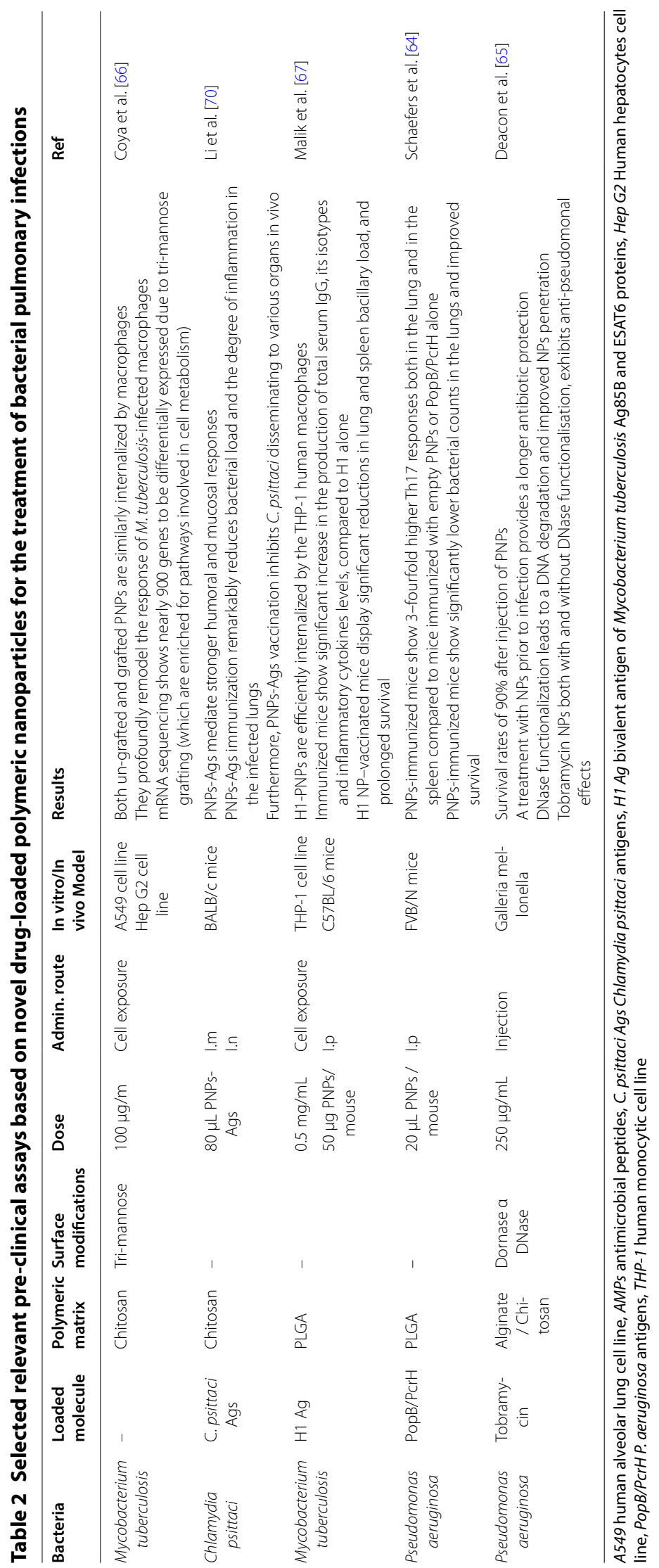


related to oral cavity infections interventions exceed $\$ 120$ billion [72]. In addition, drug retention in the oral cavity remains a major challenge, thus limiting the clinical practice incorporation of many anti-biofilms active compounds [73]. All of these reasons have triggered the development of various PNPs in recent years to treat oral cavity infections (Table 3 ).

Streptococcus mutans and Candida albicans are the two pathogens which are commonly associated to aggressive dental caries, most frequently affecting children from developing countries [74-76]. Importantly, both bacteria interact synergistically in forming dualspecies biofilms, which hardly complicate their treatment. Since chitosan NPs have proven to be effective against a broad spectrum of pathogens, Ikono et al. evaluated their effect on dental caries-associated to $S$. mutans and C. albicans biofilms [77]. Obtained results showed that PNPs significantly decrease the cell viability of both pathogens in a concentration dependent manner. Moreover, although biofilm mass is not reduced in the first hours with these PNPs, a greater inhibition of biofilm growing is observed at $18 \mathrm{~h}$ of chitosan NPs incubation in the site of action. Similarly, Sims and colleges explored the potential of PNPs as a therapeutic tool against $S$. mutans oral biofilms. In this case, authors developed two novel $\mathrm{pH}$-responsive PNPs containing farnesol (a hydrophobic antibacterial drug) and thonzonium bromide (a highly potent, FDA-approved antibacterial drug), respectively [78]. In this case, authors found that both developed PNPs markedly amplify the antibiofilm activity of loaded molecules, showing reductions of $\sim 2$ to $6 \log$ CFUs. Furthermore, farnesol-loaded PNPs are able to reduce total biomass by disrupting insoluble glucan formation. All these findings open a new window for the local treatment of dental caries caused by $S$. mutans biofilms.

Another interesting study related to oral biofilms was performed by Liu et al. who developed micellar PNPs which possess $\mathrm{pH}$ adaptivity to self-target to the acidic environment of bacteria biofilm. This carrier was composed by a PEGylated poly( $\beta$-amino esters) matrix, surface conjugated with triclosan, a potent bactericidal and fungicidal agent. Its effectiveness was evaluated both in in vitro and in vivo models of MDR $S$. aureus and $E$. coli oral biofilms[79]. In vitro results showed that PEG-PAEtriclosan are more efficient in killing MDR S. aureus, $E$. coli and oral streptococcal biofilms than free triclosan. Furthermore, in vivo assays showed that these PNPs also yield better eradication efficacy towards a MDR $S$. aureus-infection compared to free triclosan, exhibiting a bacterial killing at 30-40 fold lower triclosan-equivalent concentrations than achieved by triclosan in solution in the ex vivo analysis.
Mahmoud et al. also explored the potential of PNPs in the therapeutic approach of bacterial oral infections, in this case of Porphyromonas gingivalis, one of the most common periodontal pathogens in humans [80]. It has been shown that the interaction between commensal streptococci and P.gingivalis significantly promotes the colonization of the oral cavity by $P$. gingivalis. This study describes the development of PLGA NPs surfacemodified with BAR, a peptide derived from Streptococcus gordonii, which has previously shown to effectively inhibit the adherence of $P$. gingivalis to streptococci, thus reducing $P$. gingivalis periodontitis. Since BAR is mainly effective when biofilm is not yet established, the aim of this work was to improve the effect of BAR by PNPs targeting and bioaccumulation, to significantly disrupt an already established $P$. gingivalis $/ S$. gordonii biofilm [81]. Obtained results showed that developed nanocarrier significantly improve bone loss and IL-17 expression (analysed parameters of periodontal infection) of infected animals. Moreover, PNPs shown to be safe for gingival keratinocytes and red blood cells both in vitro and in vivo. Thus, this therapeutic alternative highlights the potential of PNPs as a biocompatible platform for local translatable oral biofilm applications.

Similarly, Toledano-Osorio et al. developed three different PNPs loading respectively zinc $(\mathrm{Zn})$, calcium $(\mathrm{Ca})$ and doxycycline, and evaluated their efficacy against several bacteria involved in oral infections, such $P$. gingivalis, S. gordonii or S. mutans, among others[82]. Authors demonstrated that developed PNPs are able to reduce the bacterial viability, been the doxycycline PNPs the most effective, reducing viability almost up to $99 \%$, followed by $\mathrm{Ca}$ PNPs and Zn PNPs. Furthermore, they also found that the most PNPs-susceptible bacteria are $P$. gingivalis, S. mutans and L. lactis, and being S. gordonii and S. sobrinus the most resistant.

\section{Polymeric nanoparticles for gastrointestinal tract infections}

Causes of gastrointestinal infections include viral, bacterial, parasitic and fungal pathogens. They vary among different geographical regions, and are compromised by co-morbidities and host immune status [1]. Bacteria are responsible for $20-40 \%$ of diarrhoeal episodes worldwide, thus contributing to high rates of childhood mortality in developing regions, and substantial morbidity and economic losses in developed regions [83]. Due to the severity of these diseases, many authors are been recently analysing the potential of PNPs to improve the pharmacological properties of existing antibiotics and/or to explore novel therapeutic alternatives (Table 4).

As explained above, $V$. cholerae is the bacterium that causes cholera in humans and the most common cause 


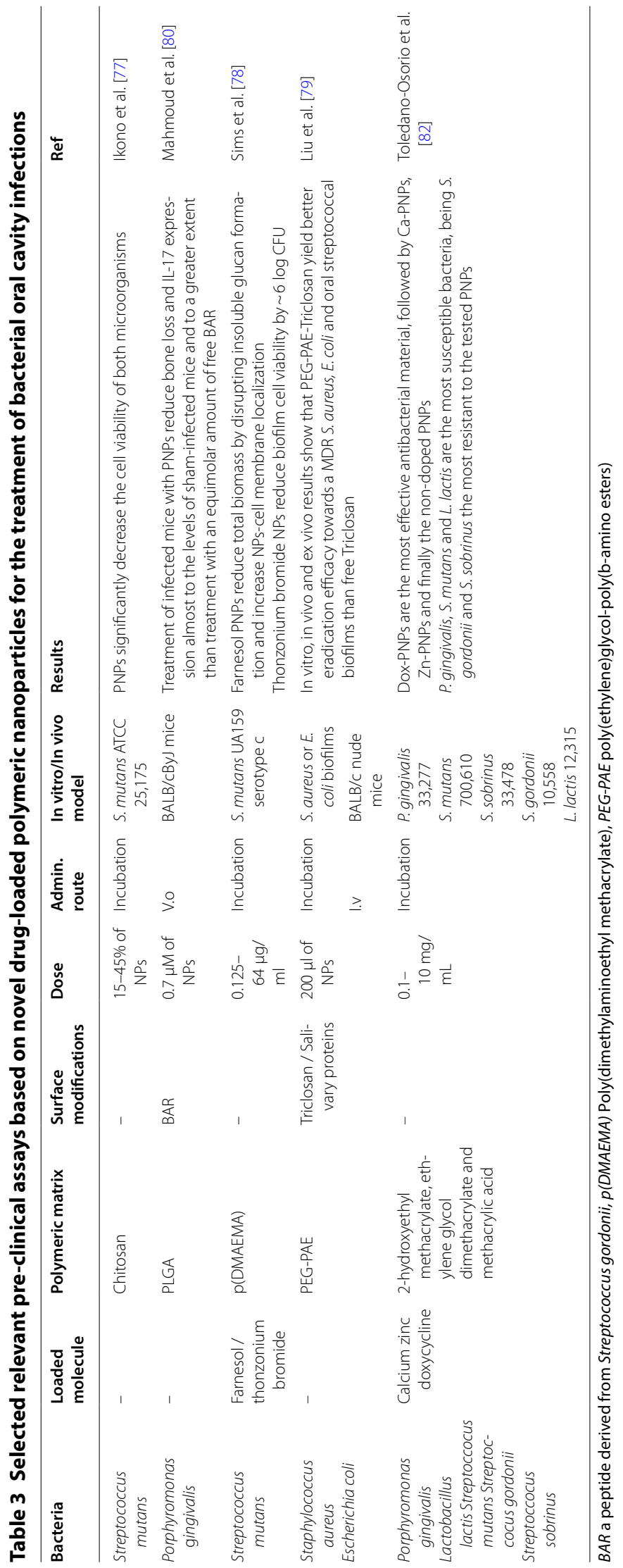




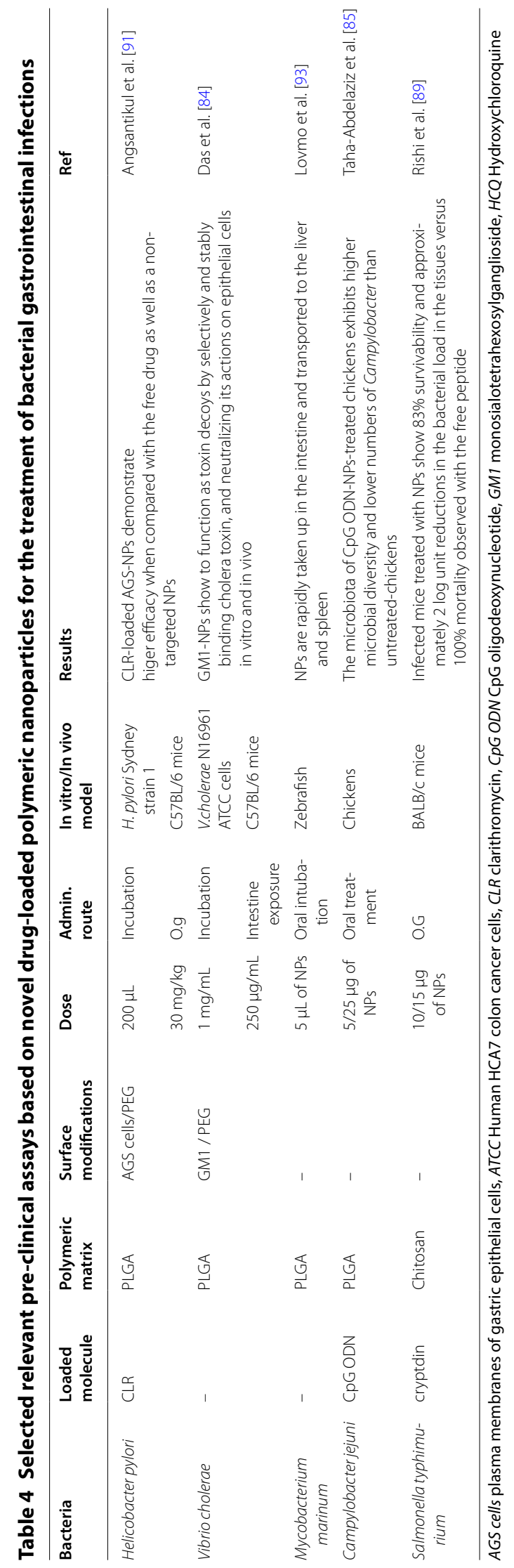


of bacterial diarrhoea worldwide [14]. As happens with other bacterial infections, the appearance of MDR has promoted an urgent need to develop alternative treatments against $V$. cholera. In that sense, Das and colleges designed surface modified PLGA NPs with PEG and GM1, a key host receptor for choler toxin, as a recruitment and clearance tool of enterotoxin [84]. Obtained results demonstrated that these PNPs are able to selectively and stably binding cholera toxin, thus neutralizing its actions. Moreover, developed PNPs attenuate the production and fluid responses of epithelial $3^{\prime}, 5^{\prime}$-cyclic adenosine monophosphate both in in vitro and in vivo models of $V$. cholera infection.

Gastroenteritis is one of the most common gastrointestinal disorders in humans, and is caused by a few pathogens, among which $C$. jejuni stands out. Farm chickens are an important reservoir of $C$. jejuni and although it does not cause clinical symptoms in these animals, it can be transmitted to humans by consumption of undercooked poultry chicken meat contaminated by intestinal contents. Reducing the $C$. jejuni colonization of gastrointestinal tract of farm chickens would lead to a reduction of incidence of human gastroenteritis. Related to that, Taha-Abdelaziz et al. developed PNPs containing CpG oligodeoxynucleotide (ODNs), a short synthetic DNA sequence highly prevalent in bacterial DNA, in order to evaluate their potential effectiveness in reducing C. jejuni burden in chickens [85]. ODNs have shown to bind to and activate Toll-like receptor 9 , which initiate an innate immune response that subsequently promotes the development of an adaptive immunity against the bacteria to which originally belong [86]. The authors found that developed PNPs are able to reduce the intestinal burden of $C$. jejuni in chickens, protect the intestinal epithelium and improve systemic immune responses of these animals. The administration of these PNPs together with $C$. jejuni lysate enhances the proliferation of specific microbial groups that reduce the colonization of $C$. jejuni.

Another bacteria pathogen associated with gastroenteritis and diarrhoea disorders is Salmonella spp., which has become a major public health problem worldwide [87, 88]. MDR issues also compromise antibiotic treatment of Salmonella infections, thus efforts in identifying an alternative therapeutic approach against Salmonella are gaining much interest. Cryptdins, Paneth cell peptides, have been reported to own bactericidal activity against several intestinal pathogens. To improve their pharmacological properties, Rishi and colleges developed cryptdin-loaded chitosan NPs to test their effect in a mice model of Salmonella typhimurium gastrointestinal infection [89]. Developed PNPs significantly increase the survival ratio of treated mice, whereas $100 \%$ mortality was observed with the free peptide treatment. Furthermore, cryptdin-loaded PNPs are able to decrease the levels of oxidant molecules, increase the level of antioxidants ones, thus all together has been the first pre-clinical report of cryptdin effectiveness by its suitable encapsulation.

Helicobacter pylori is a gram-negative, helical bacillusshaped bacterium that lives in the human stomach exclusively. Although, infected individuals may never have any symptoms, $H$. pylori infection can produce inflammation of the gastric mucosa that can progress leading to gastritis, peptic ulcer, and mucosa-associated lymphoid tissue lymphoma, thus posing a significant healthcare burden worldwide [90]. Related to that, Angsantikul et al. recently developed clarithromycin-loaded PLGA surface modified NPs with PEG and molecules of plasma membranes of gastric epithelial cells [91]. Nowadays, triple therapy based on a combination of clarithromycin, proton pump inhibitor and an antibiotic, such metronidazole or amoxicillin, is recommended for the treatment of $H$. pylori infection, but its recent mutations and subsequent drug resistance significantly compromised the success of this therapeutic option [92]. In this study, authors found that, as it was expected, developed PNPs mostly accumulate on the bacterial surface in an in vitro model of $H$. pylori. Moreover, surface modified-PNPs exhibit a higher therapeutic efficacy in mouse model of $H$. pylori infection, when compared with the free clarithromycin and to the non-targeted PNPs. Overall, these results illustrate the potential of using natural host cell molecules to functionalize PNPs for targeting and delivering of antibiotics against pathogens that colonize on that host cells.

Finally, to analysed the biodistribution of PNPs in an in vivo infection model, an innovative study carried out by Lovmo et al. evaluated the absorption and interactions of PLGA NPs with epithelial cells and the mucosal immune system of a zebrafish in vivo model of Mycobacterium marinum infection, an opportunistic bacteria in humans [93]. By fluorescence imaging, authors found that PNPs, as well as bacteria, are rapidly taken up in the intestine and mainly transported to the spleen and liver. Furthermore, in these organs, both PNPs and M. marinum bacteria cells are largely localized to leukocytes, presumably macrophages.

\section{Polymeric nanoparticles for skin infections}

Bacterial skin infections e.g. folliculitis, impetigo, furunculosis, and wound infections, among others, are the most common type of skin infections [94]. Recent studies have explored the potential of PNPs as a promising therapeutic alternative for skin infections (Table 5). The major problem resulting from wound infections caused by MRSA is the colonization of other organs, which lead to an invasive and deep infection, resulting in systemic bacteraemia and significant morbidity and mortality. 


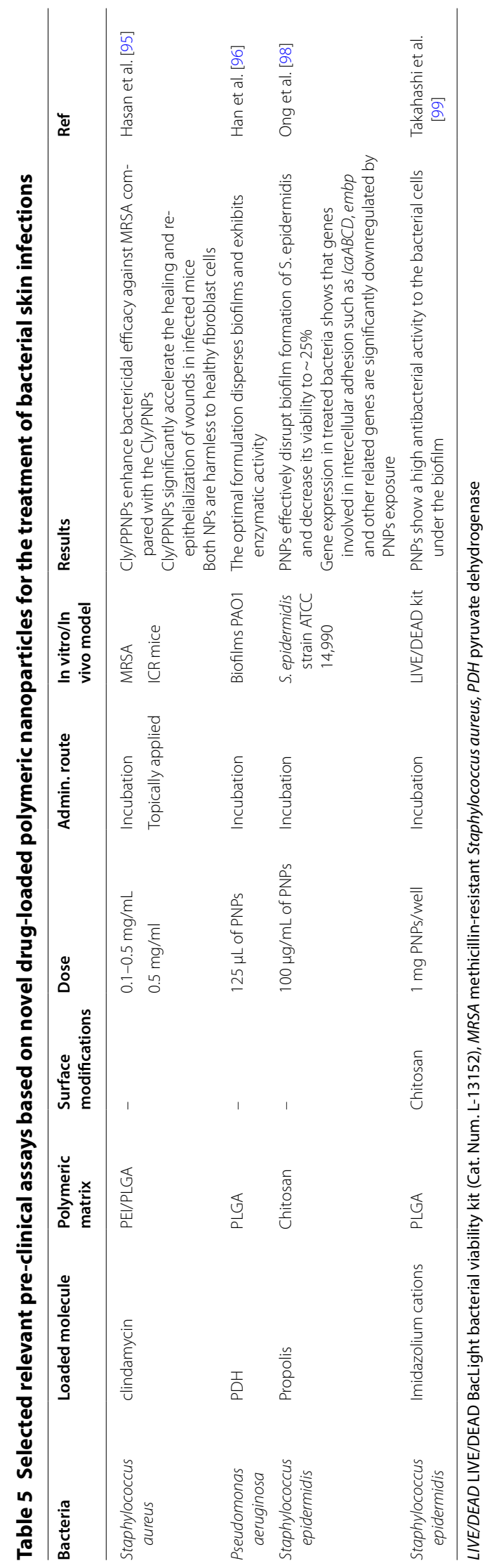


Related to this, Hasan et al. developed mixed PNPs based on PLGA/PEI with loaded clindamycin, a semisynthetic antibiotic, derived from lincomycin, effective against aerobic gram-positive cocci and anaerobic gram-negative bacilli. The developed nanocarrier was tested in a MRSA culture and ICR mice model of cutaneous wound infection [95]. Authors found that developed PNPs are able to efficiently bind to the MRSA surface, thus enhancing the bactericidal activity of clindamycin. Moreover, clindamycin-loaded PNPs significantly accelerate the healing and re-epithelialization of wounds in the in vivo assay, without compromising the healthy fibroblast cells activity.

Another pathogen found in chronic wound infections, as well as burn wound infections, is $P$. aeruginosa. Han et al. developed enzyme-encapsulated PLGA NPs and evaluated their effectiveness against biofilms formed by P. aeruginosa PAO1 [96]. Selected enzyme was pyruvate dehydrogenase, since it has been previously described that $P$. aeruginosa biofilm are reverted to an antibioticsusceptible state via pyruvate-depletion induced dispersion [97]. Obtained results showed that developed PNPs extended the activity of this enzyme, thus leading to the dispersion of preformed biofilms.

Staphylococcus epidermidis, a common microbiota of human body, can originate opportunistic infections associated with indwelling medical devices. It shows a strong MDR activity, which promotes the need to find new pharmacological alternatives. In this context, Ong and colleges designed chitosan NPs carrying malasyan propolis to evaluate their efficacy against this opportunistic pathogen [98]. Malaysian propolis, obtained from beehives, is a natural product that exhibits significant antimicrobial activity. Authors found that developed PNPs are able to effectively disrupt $S$. epidermidis biofilm formation and decrease the bacteria viability to $\sim 25 \%$. Moreover, propolis-loaded PNPs downregulate genes involved in intercellular bacteria adhesion, and exhibit a synergism with ciprofloxacin, rifampicin, doxycycline and vancomycin. Thus, combination therapy represents a way of tackling antibiotic resistance in S. epidermidis infections. Similarly, Takahashi et al. evaluated the potential of PNPs as a novel tool against S. epidermis biofilm skin infections. In this case, polymeric matrix was composed by PLGA, and imidazolium cations were loaded as active compound [99]. These molecules present some advantages, such as good biocompatibility, high permeability to bacteria cell wall, and significant antimicrobial activity. Thus, by using a LIVE/DEAD BacLight bacterial viability kit, authors demonstrated that developed PNPs possess a high antibacterial activity to the bacterial cells forming the biofilm, establishing a suitable drug delivery system to enhance the potential of polymeric nanocarriers for treating biofilm infections.

\section{Polymeric nanoparticles for urinary tract infections}

Urinary tract infections are the most common outpatient infections, with a lifetime incidence of $50-60 \%$ in adult women [100]. The prevalence of urinary infection is $0.7 \%$ worldwide, being the age, sexual activity and diabetes the main risk factors. The most common pathogen is Escherichia coli. Importantly, resistance rates of most common antibiotic drugs of urinary tract are increasing over the years, and are significantly governed by geographical location [101]. For these reasons, in the last years, several nanotechnological platforms have been exploited for the treatment of urinary tract infections (Table 6).

$E$. coli is a gram-negative bacillus bacterium that is part of the normal microbiota of the gastrointestinal tract in humans. However, different strains have been shown to acquire genetic mutations that are related to virulence factors [102]. These strains have been associated with gastrointestinal, urinary tract, blood or nervous system infections. The high morbidity, as well as the variety in syndromes and clinical symptoms associated with $E$. coli infections, make this bacterium one of the most versatile pathogens of great relevance to humans [103]. Several studies have evaluated the potential of PNPs as therapeutic tool against E. coli urinary tract infections. Related to this, Ashmore and colleges compared the antibacterial efficacy of polymer-coated silver NPs with the non-coated ones [104]. The coating of silver NPs with polymer significantly improves the antibacterial efficacy of the particles. In addition, polymer-coated silver NPs also promote a downregulation of the expression of genes associated with the citric acid cycle and amino acid metabolism, which are involved in the cellular growth of E coli. Similarly, Alfaro-Viquez et al. developed proanthocyanidin-chitosan NPs against bacterial colonization of gut epithelial cells by extra-intestinal pathogenic E. coli (ExPEC) [105]. ExPEC are the primary cause of urinary tract infections, of which $20 \%$ to $45 \%$ have shown resistance to antibiotics [102]. Cranberry proanthocyanidins have widely shown to be effective in the treatment of acute cystitis, which indicate that could be a potential alternative as antimicrobial therapy of ExPEC infections. However, the antioxidant properties of these compounds make them very susceptible to degradation, thus reducing their pharmacological effectiveness. This study revealed that developed PNPs protect proanthocyanidins from oxidation and decrease the ability of ExPEC to invade epithelial cells in a dose-dependent manner.

Co-infections commonly occur in urinary tract. There is a wide variety of bacteria that can colonize human urinary tract and also related medical devices (e.g. catheters or ureteral stents). Kumar et al. explored the surface immobilization of kanamycin-loaded PNPs to prevent the bacterial biofilm formation in urethral stents [106]. 


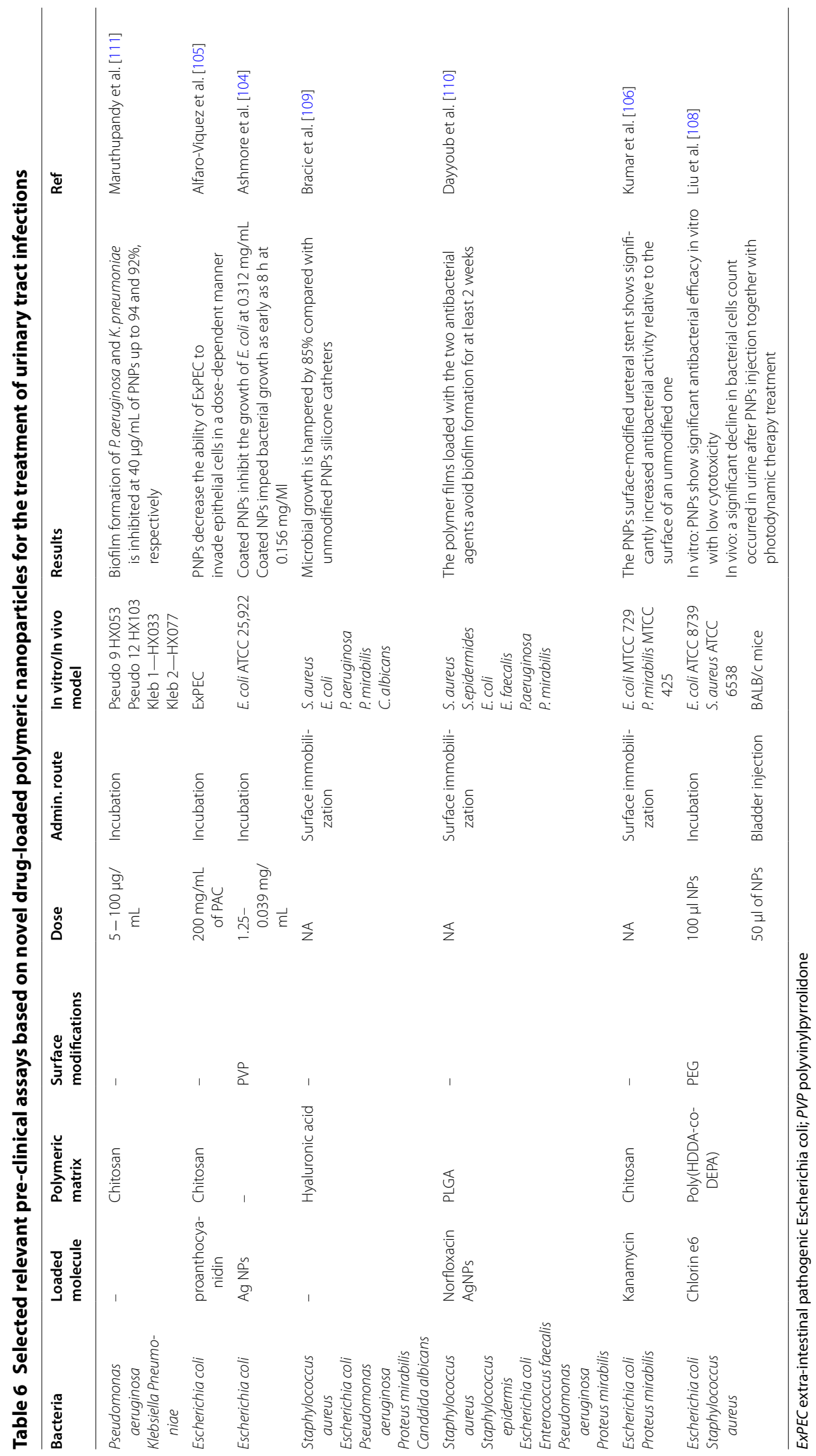


Kanamycin is an aminoglycoside antibiotic used to treat Gram-negative and some Gram-positive bacterial infections. Recently, is has been shown that combination of antibiotics with chitosan matrices significantly improve the antibacterial activity of these molecules and reduce the resistance of several bacteria [107]. In this study, authors reported that, after a covalent immobilization of developed kanamycin-loaded PNPs onto the surface of an urethral stent, it is observed a significant reduction of E. coli and P. mirabilis activity, the selected bacteria. Similarly, an interesting work developed by Liu et al. explored a therapeutic alternative for urinary co-infections of $E$. coli and $S$. aureous, which involved the combination of antimicrobial photodynamic therapy together with PNPs [108]. The technique was based on the photostimulation of Chlorin e6 encapsulated charge-conversion PNPs by a laser irradiation, which generates the production of reactive oxygen species (ROS) and subsequently killing of pathogenic bacteria under an acidic environment. This innovative technique was evaluated in both in vitro and in vivo models. Obtained results showed that PNPs are able to better recognise Gram-positive (S. aureus) and Gram-negative ( $E$. coli) bacteria due to the charge interaction, together with a significant in vitro antibacterial efficacy and reduced cytotoxicity. Moreover, in a mouse acute cystitis model, authors found a significant decline in bacterial cells counts in the urine of NPs-treated animals compared to those treated with free drug, as well as in the bladder tissue after sacrifice.

Another interesting study carried out by Bracic et al. explored the immobilization of PNPs composed by hyaluronic acid and a lysine-derived biocompatible cationic surfactant in silicone catheters to evaluate their efficacy against five different colonizing bacteria of urinary tract medical devices [109]. In this case, obtained results revealed that that the microbial growth is hampered almost by $85 \%$ compared to unmodified silicone catheters. Taking a step further, Dayyoub et al. developed silver NPs coated with PLGA carrying norfloxacin, a broad-spectrum synthetic antibiotic almost exclusively indicated in the treatment of urinary tract infections [110]. These PNPs were used to coat polyurethane and silicon sheets. This coating prevents the bacterial adhesion of artificial urine and an in vitro encrustation model for at least 2 weeks.

$P$. aeruginosa and $K$. pneumoniae are not only colonizers of the respiratory tract, but also of the urinary tract. Related to that, Maruthupandy et al. recently developed graphene/chitosan NPs against $P$. aeruginosa and K. pneumoniae biofilms [111]. With this study authors demonstrated that the viability of both uropathogens is reduced almost 95\% when incubated with developed hybrid NPs.

\section{Polymeric nanoparticles for neuroinfections}

Central nervous system (CNS) infections can be caused by different agents (e.g. viruses, bacteria, parasites, fungi) and, in rare occasions, by prions infections. Meningitis and encephalitis are the most common neuroinfections in humans, which involve the inflammation of the whole brain of the meninges, the membranes that surround the brain and spinal cord, producing a high impact on tissue homeostasis [112]. There is a different etiological epidemiology of meningitis and encephalitis in different geographical regions; pathogens vary across different age groups, seasons and geographic locations. Viruses account for most cases of meningitis and encephalitis. Viral meningitis and encephalitis are usually benign and self-limiting, while bacterial meningitis and encephalitis can lead to disastrous damage [113]. The cardinal clinical symptoms and signs are mainly indistinguishable regardless of the inciting pathogen [114].

CNS infections cause significant morbidity and mortality and often require neurosurgical intervention for proper diagnosis and treatment. Regarding to WHO, Africa had the highest pooled incidence of bacterial meningitis (65 cases/100,000 people) [115]. Approximately 304,000 meningitis patients and 77,000 encephalitis patients died all over the world in 2013 comparing to 46,4000 and 92,000 in 1990 respectively [116].

One of the main limitations during bacterial neuroinfections treatment is the inability of antibiotics to surpass the $\mathrm{BBB}$ and the blood-cerebrospinal fluid barrier (BCSFB), as well as the emerging of antibiotic resistance. To this end, drug targeting approaches are being recently used to overcome these issues [117]. Getting a local antimicrobial treatment, the concentration of the drug at the site of infection will be improved, as it may modulate drug-pathogen interaction to overcome antibiotic resistance, and enabling 'drug-free' anti-virulence therapy [26]. In this context, many studies have been conducted in order to improve antibacterial and antivirals compounds effectiveness by using of nanotechnology (Table 7).

$N$. meningitidis is a leading cause of bacterial meningitis and its capsular polysaccharides the basis for serogroup designation and preventive vaccines [118]. Related to that, Gala et al. recently developed a novel meningococcal nanoparticulate vaccine that slowly release those antigens, and evaluated the possibly antigen depot effect to enhance antigenicity [119]. In order to enhance the antigenicity of the vaccine, various adjuvants were evaluated. Results showed that PNPs enhance dendritic cell maturation and antigen presentation markers MHC I, MHC II, CD40, CD80 and CD86 in this cell line pulsed with meningococcal nanoparticulate vaccine. Similarly, Long et al. developed PNPs to carry amphiphilic 


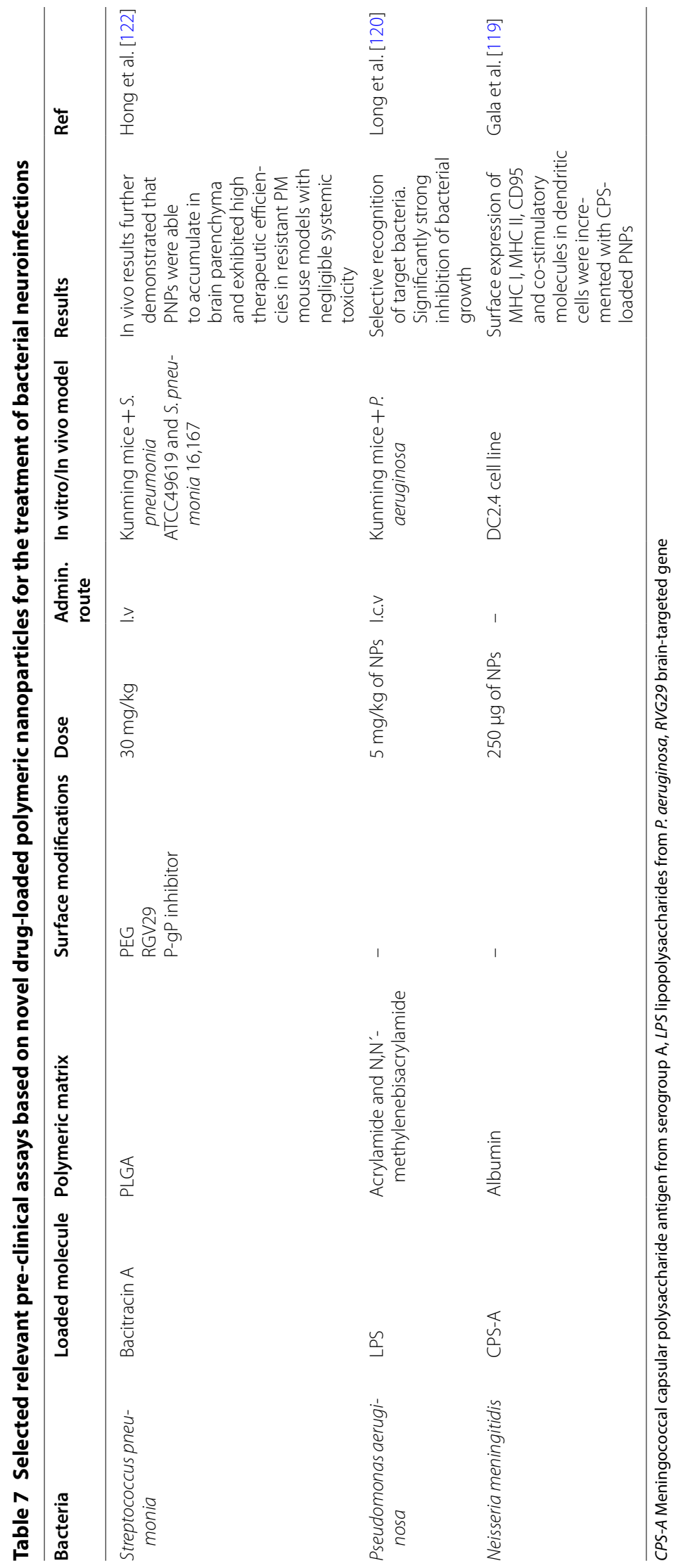


lipopolysaccharides, derived from $P$. aeruginosa to test their effectiveness in a mice model of meningitis [120]. $P$. aeruginosa has been shown also to infect the brain and spinal cord, and lead to meningitis, brain abscesses, and potentially death [121]. Authors found that developed PNPs promote a selective recognition of target bacteria and exhibit targeting capacity in vivo. Moreover, this nanocarrier presents a strongly inhibited bacterial growth, compared to those controls of the in vitro assays.

The incidence of CNS bacterial infections is associated with the immunosuppressive drug treatments and increased prescription of antibiotics. Immunosuppression is usually followed by immunodeficiency disease, which led to those serious infections and, in case of CNS, $\mathrm{BBB}$ compromises the cumulative of antibacterial agents. In this context, Hong et al. developed a PEGylated-polymeric nanocarrier of bacitracin A coated with a specific brain-targeting peptide and a P-glycoprotein inhibitor against Pneumococcal meningitis (122). This study revealed the enhanced BBB-permeability attributed to the synergetic effect of both coating peptides. In vivo results further demonstrated that developed PNPs are able to accumulate in brain parenchyma and exhibit high therapeutic efficiency with negligible systemic toxicity compared to the free drug.

\section{Conclusions}

The rise of the number of individuals affected by bacterial infectious diseases constitutes a significant socioeconomic health burden worldwide and is mainly related to economic and public health problems in developing countries, and nosocomial infections in developed countries. Even when promising therapeutic molecules are available, the appearance of MDR events has established itself as a serious public health problem worldwide. The widespread misuse of antibiotic drugs has promoted genetic mutations and smart evasion mechanisms by bacteria that have led to an important failure in these therapies. As reviewed herein, nanotechnologies applied to medicine-nanomedicine-have opened new therapeutic opportunities for the treatment of bacterial infections. Specifically, state-of-the-art PNPs have demonstrated to possess optimal physicochemical characteristics to become a therapeutic revolution against human bacterial infections. This type of nanocarriers have shown to be safe, biodegradable, biocompatible, easily eliminated and non-toxic for the tissues and organs, offer many advantages for currently available molecules. Moreover, the targeting to a specific organ, the reduction of the adverse effects of many antibiotics, and prolonged accumulation over time in the infected area, altogether represent a breakthrough in this kind of therapy. Furthermore, polymers themselves have shown to be effective against multiple antibiotic resistant bacteria. Thus, the combination of loaded drugs together with polymeric matrices may offer a synergistic approach with innovative outputs and may represent the next step in the treatment of bacterial infections.

Research in the next few years will increasingly focus on the elucidating and better understanding of the molecular mechanisms of bacteria involved in MDR events to re-direct the drugs targets. Whilst PNPs are undoubtedly among the most efficient tools to overcome MDR bacteria problems, clinical translation of nanoparticles-based treatments remains a challenge for the pharmaceutical industry, since nanotechnology has not yet entered mainstream clinical practice. Stringent protocols of validation of in vitro and in vivo protocols are necessary to facilitate translation from bench to the clinical trials. Likewise, challenges for large scale manufacturing require innovation from chemists and engineers and regulatory policies have to be adapted to facilitate access to trials and patients. Thus, despite the huge progress in preclinical research, the translation of these drug delivery systems to clinical practice remains one of the most ambitious challenges in this field, and will be a major focus of most nanomedicine trials in the next decade.

Finally, the social gap between developed and developing countries, which is closely related to the rise of these diseases, is another of the important challenges that we face as a society. The development of a global community structure that ensures access to antibiotic drugs and their correct use, and effective public health measures will represent an advance against bacterial infections worldwide.

\section{Abbreviations}

AMP: Antimicrobial polymers; BBB: Blood-brain barrier; BCSF: Blood-cerebrospinal fluid barrier; CFUs: Colony forming units; CNS: Central nervous system; EXPEC: Extra-intestinal pathogenic E. coli; LRI: Lower respiratory infections;

MDR: Multidrug resistant; MRSA: Methicillin-resistant S. aureus; NO: Nitric oxide NPs, nanoparticles; ODNs: CpG oligodeoxynucleotides; PEl: Polietilenimina; PLGA: Poly(lactic-co-glycolic acid); PNPs: Polymeric nanoparticles; PopB: P. aeruginosa Type III secretion system protein; ROS: Reactive oxygen species; WHO: World Health Organization; YLDs: Years of life lived with disability.

\section{Acknowledgements}

Authors acknowledge the support of the Spanish Ministry of Economy and Competitiveness (SAF2017-84283-R and RTI2018-098641-B-I00), Biomedi-

cal Research Networking Centre in Neurodegenerative Diseases (CIBERNED, CB06/05/0024), Scientific Project Marató TV3 (ref 201829-10) and European Regional Development Founds. Authors also acknowledge the Portuguese Science and Technology Foundation (FCT) for the strategic fund (UIDB/04469/2020).

\section{Authors' contributions}

AC: Proposal and schematization of the article, Bibliography search, Content analysis \& selection, Writing-original full draft, Re-writing of manuscript revisions. ME: Bibliography search, Writing-original draft section. ME: Writingreview \& editing. ALM: Bibliography search, Editing figures \& tables, Re-writing of manuscript revision. YC: Writing-review \& editing. FR: Writing-review \& editing. ESL: Bibliography search, Writing-original draft section. AC: Writing-review 
\& editing, Linguistic correction. MLG: Content analysis \& selection, Writingreview \& editing. EBS: Writing-review \& editing, Linguistic correction. All authors read and approved the final manuscript.

\section{Funding}

Review Manuscript. Not applicable.

\section{Availability of data and materials}

Review Manuscript. Not applicable.

\section{Ethics approval and consent to participate}

Review Manuscript. Not applicable.

\section{Consent for publication}

The corresponding author of this manuscript, Dr. Amanda Cano, on behalf of all co-authors (Miren Ettcheto, Marta Espina, Ana López-Machado, Yolanda Cajal, Francesc Rabanal, Elena Sánchez-López, Antonio Camins, Maria Luisa García and Eliana B. Souto) declares the consent of publication of this manuscript in the Journal of Nanobiotechnology. All authors have read and approved the submitted final version.

\section{Competing interests}

None of the authors has any conflicts of interest including any financial, personal or other relationships with other people or organizations. All authors have reviewed the contents of the manuscript being submitted and approved its contents.

\section{Author details}

${ }^{1}$ Department of Pharmacy, Pharmaceutical Technology and Physical Chemistry, Faculty of Pharmacy and Food Sciences, University of Barcelona, Av Joan XXIII, 27-31, 08017 Barcelona, Spain. ${ }^{2}$ Institute of Nanoscience and Nanotechnology (IN2UB), Barcelona, Spain. ${ }^{3}$ Biomedical Research Networking Centre in Neurodegenerative Diseases (CIBERNED), Madrid, Spain. ${ }^{4}$ Department of Pharmacology, Toxicology and Therapeutic Chemistry, Faculty of Pharmacy and Food Sciences, University of Barcelona, Barcelona, Spain. ${ }^{5}$ Unit of Biochemistry and Pharmacology, Faculty of Medicine and Health Sciences, University of Rovira I Virgili, Reus (Tarragona), Spain. ${ }^{6}$ Section of Organic Chemistry, Department of Inorganic and Organic Chemistry, Faculty of Chemistry, University of Barcelona, Barcelona, Spain. ${ }^{7}$ Department of Pharmaceutical Technology, Faculty of Pharmacy, University of Coimbra, Coimbra, Portugal. ${ }^{8}$ CEB - Centre of Biological Engineering, University of Minho, Campus de Gualtar, 4710-057 Braga, Portugal.

\section{Received: 31 July 2020 Accepted: 21 October 2020} Published online: 31 October 2020

\section{References}

1. World Health Organization (WHO). Global health estimates 2016: disease burden by cause, age, sex, by country and by region, 2000-2016 [Internet]. 2018. https://www.who.int/healthinfo/global_burden_disea se/estimates/en/index1.html. Accessed 28 Oct 2020.

2. Rappuoli R, Bloom DE, Black S. Deploy vaccines to fight superbugs. Nature. 2017;552:163-7.

3. Khali IA, Troeger C, Blacker BF, Rao PC, Brown A, Atherly DE, et al. Morbidity and mortality due to shigella and enterotoxigenic Escherichia coli diarrhoea : the Global Burden of Disease Study 1990-2016. Lancet Infect Dis. 2018;18:1229-40.

4. GBD. Estimates of the global, regional, and national morbidity, mortality, and aetiologies of diarrhoea in 195 countries : a systematic analysis for the Global Burden of Disease Study 2016. Lancet Infect Dis. 2018a; 18:1211-28.

5. GBD. Global, regional, and national burden of meningitis, 1990-2016: a systematic analysis for the Global Burden of Disease Study 2016. Lancet Neurol. 2018b;17:1061-782.

6. GBD. Global, regional, and national burden of tuberculosis, 1990-2016 : results from the Global Burden of Diseases, Injuries, and Risk Factors 2016 Study. Lancet Infect Dis. 2018c;18:1329-49.

7. Rudd KE, Johnson SC, Agesa KM, Shackelford KA, Tsoi D, Kievlan DR, et al. Global, regional, and national sepsis incidence and mortality,
1990-2017: analysis for the Global Burden of Disease Study. Lancet. 2020;395:200-11.

8. Collignon PJ, McEwen SA. One health-its importance in helping to better control antimicrobial resistance. Trop Med Infect Dis. 2019;4(1):22.

9. Doron S, Gorbach S. Bacterial infections : overview. In: International Encyclopedia of Public Health. Amsterdam: Elsevier; 2008;273-282. 10.1016/B978-012373960-5.00596-7

10. Santajit S, Indrawattana N. Mechanisms of antimicrobial resistance in ESKAPE pathogens. Biomed Res Int. 2016;2016:2475067.

11. Hollingshead S, Tang CM. An overview of Neisseria Meningitidis. Methods Mol Biol. 2019;1969:1-16.

12. Young $N$, Thomas M. Meningitis in adults: diagnosis and management. Intern Med J. 2018;48(11):1294-307.

13. Conner JG, Teschler JK, Jones CJ, Yildiz FH. Staying alive: vibrio cholerae's cycle of environmental survival, transmission, and dissemination. Microbiol Spectr. 2016;4(2):10.

14. Lekshmi N, lype J, Ramamurthy T, Sabu T. Changing facades of Vibrio cholerae: an enigma in the epidemiology of cholera. Indian J Med Res. 2018;147(2):133-41.

15. Burke KE, Lamont JT. Clostridium difficile infection: a worldwide disease. Gut Liver. 2014;8(1):1-6.

16. Ooijevaar RE, Van BYH, Terveer EM, Goorhuis A, Bauer MP, Keller JJ, et al. Update of treatment algorithms for Clostridium difficile infection. Clin Microbiol Infect. 2018;24(5):452-62.

17. Le Chevalier F, Cascioferro A, Majlessi L, Herrmann JL, Brosch R. Mycobacterium tuberculosis evolutionary pathogenesis and its putative impact on drug development. Future Microbiol. 2014;9(8):969-85.

18. Tiberi S, du Plessis N, Walzl G, Vjecha MJ, Rao M, Ntoumi F, et al. Tuberculosis: progress and advances in development of new drugs, treatment regimens, and host-directed therapies. Lancet Infect Dis. 2018;18(7):e183-98.

19. Witkin SS, Minis E, Athanasiou A, Leizer J, Linhares IM. Chlamydia trachomatis: the persistent pathogen. Clin Vaccine Immunol. 2017;24(10):e00203-e217.

20. Lane AB, Decker CF. Chlamydia trachomatis infections. Dis Mon. 2016;62(8):269-73.

21. Singh S, Hussain A, Shakeel F, Ahsan MJ, Alshehri S, Webster TJ, et al. Recent insights on nanomedicine for augmented infection control. Int J Nanomed. 2019;14:2301-25.

22. Kamaruzzaman NF, Tan LP, Hamdan RH, Pina MDF. Antimicrobial polymers : the potential replacement of existing antibiotics? Int J Mol Sci. 2019;20(2747): 1-31.

23. Aminov Rl. A brief history of the antibiotic era : lessons learned and challenges for the future. Front Mocrobiol. 2010;1:134.

24. European Commission [Internet]. EU Action on Antimicrobial Resistance. 2020. https://ec.europa.eu/health/amr/antimicrobial-resistance _en. Accessed 28 Oct 2020.

25. Centers for Disease Control and Prevention [Internet]. 2019 AR Threats Report. 2019. https://www.cdc.gov/drugresistance/biggest-threa ts.html. Accessed 28 Oct 2020.

26. Gao W, Chen Y, Zhang Y, Zhang Q, Zhang L. Nanoparticle-based local antimicrobial drug delivery. Adv Drug Deliv Rev. 2018;127:46-57.

27. Masri A, Anwar A, Khan NA. The use of nanomedicine for targeted therapy against bacterial infections. Antibiotics. 2019;8:260.

28. Gupta A, Mumtaz S, Li C, Hussain I, Vincent M, States U. Combatting antibiotic-resistant bacteria using nanomaterials. Chem Soc Rev. 2019;48(2):415-27.

29. Lam SJ, Wong EHH, Boyer C, Qiao GG. Antimicrobial polymeric nanoparticles. Prog Polym Sci. 2018;76:40-64.

30. Sánchez-lópez E, Gomes D, Esteruelas G, Bonilla L, Lopez-machado AL, Galindo R, et al. Metal-based nanoparticles as antimicrobial agents : an overview. Nanomaterials. 2020;10(2):292.

31. AlMatar M, Makky EA, Var I, Koksal F. The role of nanoparticles in the inhibition of multidrug-resistant bacteria and biofilms. Curr Drug Deliv. 2018;15(4):470-84.

32. Chen J, Andler SM, Goddard JM, Nugen SR, Rotello VM. Integrating recognition elements with nanomaterials for bacteria sensing. Chem Soc Rev. 2017;46(5):1272-83.

33. Hamula C, Zhang H, Li F, Wang Z, Chris LX, Li X. Selection and analytical applications of aptamers binding microbial pathogens. TrAC, Trends Anal Chem. 2011;30(10):1587-97. 
34. van der Merwe R, van Helden P, Warren R, Sampson S, van Pittius NG. Phage-based detection of bacterial pathogens. Analyst. 2014;139(11):2617-26.

35. Barraud N, Kelso MJ, Rice SA, Kjelleberg S. Nitric oxide: a key mediator of biofilm dispersal with applications in infectious diseases. Curr Pharm Des. 2015;21(1):31-42.

36. Duong HTT, Adnan NNM, Barraud N, Basuki JS, Kutty SK, Jung K, et al. Functional gold nanoparticles for the storage and controlled release of nitric oxide : applications in bio fi Im dispersal and intracellular delivery. J Mater Chem B. 2014;2:5003-11.

37. Duong HTT, Jung K, Kutty SK, Agustina S, Adnan NNM, Basuki JS, et al. Nanoparticle (Star Polymer) delivery of nitric oxide effectively negates Pseudomonas aeruginosa biofilm formation. Biomacromol. 2014;15:2583-9.

38. Nguyen T-K, Selvanayagam R, Ho KKK, Chen R, Kutty SK, Rice SA, et al. Co-delivery of nitric oxide and antibiotic using polymeric nanoparticles. Chem Sci. 2016;7:1016-27.

39. Nguyen T, Duong HTT, Selvanayagam R, Boyer C. Iron oxide nanoparticle-mediated hyperthermia stimulates dispersal in bacterial biofilms and enhances antibiotic efficacy. Sci Rep. 2015;5:18385.

40. Kyzioł A, Khan W, Sebastian V, Kyzioł K. Tackling microbial infections and increasing resistance involving formulations based on antimicrobial polymers. Chem Eng J. 2020;385:123888.

41. Mowery B, Lee S, Kissounko D, Epand R, Epand R, Weisblum B, et al. Mimicry of antimicrobial host-defense peptides by random copolymers. J Am Chem Soc. 2007;129:15474-6.

42. Park A, Okhovat J, Kim J. Antimicrobial peptides. Clin Basic Immunodermatol Second Ed. 2017;1548:81-95.

43. Judzewitsch APR, Nguyen T, Wong EHH, Jean CA. Towards sequencecontrolled antimicrobial polymers: effect of polymer block order on antimicrobial activity. Angew Chem. 2018;130(17):4649-54.

44. Nguyen T, Lam SJ, Ho KKK, Kumar N, Qiao GG, Egan S, et al. Rational design of single-chain polymeric nanoparticles that kill planktonic and bio film bacteria. ACS Infect Dis. 2017;3:237-48.

45. Namivandi-Zangeneh R, Kwan RJ, Nguyen T-K, Yeow J, Byrne FL, Oehlers $\mathrm{SH}$, et al. The effects of polymer topology and chain length on the antimicrobial activity and hemocompatibility of amphiphilic ternary copolymers. Polym Chem. 2018;9(13):1735-44.

46. Namivandi-zangeneh R, Sadrearhami Z, Dutta D, Willcox M, Wong $\mathrm{EHH}$, Boyer C. Synergy between synthetic antimicrobial polymer and antibiotics: a promising platform to combat multidrug-resistant bacteria. ACS Infect Dis. 2019;5:1357-65.

47. Namivandi-zangeneh $R$, Yang $Y, X u$ S, Wong EHH, Boyer C. Antibiofilm platform based on the combination of antimicrobial polymers and essential oils. Biomacromol. 2020;21:262-72.

48. Burian M, Schittek B. The secrets of dermcidin action. Int J Med Microbiol. 2015;305:283-6.

49. Aoki W, Ueda M. Characterization of antimicrobial peptides toward the development of novel antibiotics. Pharmaceuticals. 2013;6:1055-81.

50. Le C, Fang C, Sekaran S. Intracellular targeting mechanisms by antimicrobial peptides. Antimicrob Agents Chemother. 2017;61:e02340-e2416.

51. Butler M, Blaskovich M, Cooper M. Antibiotics in the clinical pipeline at the end of 2015. J Antibiot. 2016;70:3.

52. Muñoz-Bonilla A, Fernández-García M. Polymeric materials with antimicrobial activity. Prog Polym Sci. 2012;37:281-339.

53. Park E, Moon W, Song M, Kim M, Chung K, Yoon J. Antimicrobial activity of phenol and benzoic acid derivatives. Int Biodeterior Biodegrad. 2001;47:209-14.

54. Suaifan GA, Mohammed AA. Fluoroquinolones structural and medicinal developments (2013-2018): Where are we now? Bioorg Med Chem. 2019;27(14):3005-60.

55. Lin J, Chen X, Chen C, Hu J, Zhou C, Cai X, et al. Durably antibacterial and bacterially antiadhesive cotton fabrics coated by cationic fluorinated polymers. ACS Appl Mater Interfaces. 2018;10:6124-36.

56. Mesallati H, Umerska A, Paluch K, Tajber L. Amorphous polymeric drug salts as ionic solid dispersion forms of ciprofloxacin. Mol Pharm. 2017;14:2209-23.
57. Kocer H, Worley S, Broughton R, Huang T. A novel N-halamine acrylamide monomer and its copolymers for antimicrobial coatings. React Funct Polym. 2011;71:561-8.

58. Locock KE, Michl T, Griesser H, Haeussler M, Meagher L. Structureactivity relationships of guanylated antimicrobial polymethacrylates. Pure Appl Chem. 2014;86:1281-91.

59. Mankoci S, Kaiser R, Sahai N, Barton H, Joy A. Bactericidal peptidomimetic polyurethanes with remarkable selectivity against Escherichia coli. ACS Biomater Sci Eng. 2017;3:2588-97.

60. Delplace $V$, Nicolas J. Degradable vinyl polymers for biomedical applications. Nat Chem. 2015;7:771-84.

61. Awad M, Mekhamer W, Merghani N, Hendi A, Ortashi KM, Al-Abbas F, et al. Green synthesis, characterization, and antibacterial activity of silver/polystyrene nanocomposite. J Nanomater. 2015;2015:1-6.

62. GBD and Collaborators. Estimates of the global, regional, and national morbidity, mortality, and aetiologies of lower respiratory infections in 195 countries, 1990-2016: a systematic analysis for the Global Burden of Disease Study 2016. Lancet Infect Dis. 2018;18:1191-210.

63. Maurice NM, Bedi B, Sadikot RT. Pseudomonas aeruginosa biofilms: host response and clinical implications in lung infections. Am J Respir Cell Mol Biol. 2018;58(4):428-39.

64. Schaefers MM, Duan B, Mizrahi B, Lu R, Reznor G, Kohane DS, et al. PLGA-encapsulation of the Pseudomonas aeruginosa PopB vaccine antigen improves Th17 responses and confers protection against experimental acute pneumonia. Vaccine. 2018;36(46):6926-32. https:// doi.org/10.1016/j.vaccine.2018.10.010.

65. Deacon J, Abdelghany SM, Quinn DJ, Schmid D, Megaw J, Donnelly RF, et al. Antimicrobial efficacy of tobramycin polymeric nanoparticles for Pseudomonas aeruginosa infections in cystic fibrosis: formulation, characterisation and functionalisation with dornasealfa (DNase). J Control Release. 2015;198:55-61. https://doi.org/10.1016/j.jconrel.2014.11.022.

66. Coya JM, De Matteis L, Gatineau AG, Biton A, Sevilla IS, Danckaert $A$, et al. Tri-mannose grafting of chitosan nanocarriers remodels the macrophage response to bacterial infection. J Nanobiotechnol. 2019;17(15):1-15. https://doi.org/10.1186/s12951-018-0439-X.

67. Malik A, Gupta M, Mani R, Bhatnagar R. Single-dose Ag85B-ESAT6loaded poly ( lactic- co -glycolic acid) nanoparticles confer protective immunity against tuberculosis. Int J Nanomed. 2019;14:3129-43.

68. Knittler MR, Sachse K. Chlamydia psittaci: update on an underestimated zoonotic agent. Pathog Dis. 2015;73(1):1-15.

69. Hogerwerf L, DE Gier B, Baan B, Van Der Hoek W. Chlamydia psittaci (psittacosis) as a cause of community-acquired pneumonia: a systematic review and meta-analysis. Epidemiol Infect. 2017;145(15):3096-105.

70. Li Y, Wang C, Sun Z, Xiao J, Yan X, Chen Y, et al. Simultaneous intramuscular and intranasal administration of chitosan nanoparticles-adjuvanted chlamydia vaccine elicits elevated protective responses in the lung. IJN. 2019;14:8179-93.

71. Tonetti M, Jepsen S, Jin L, Otomo-Corgel J. Impact of the global burden of periodontal diseases on health, nutrition and wellbeing of mankind: a call for global action. J Clin Periodontol. 2017;44(5):456-62.

72. Kassebaum N, Bernabe E, Dahiya M, Bhandari B, Murray C, Marcenes W. Global burden of untreated caries: a systematic review and metaregression. J Dent Res. 2015;94(5):650-8.

73. Sankar V, Hearnden V, Hull K, Vidovic Juras D, Greenberg M, Kerr A, et al. Local drug delivery for oral mucosal diseases: challenges and opportunities. Oral Dis. 2011;17(Suppl 1):73-84.

74. Meng Y, Wu T, Billings R, Kopycka-Kedzierawski DT, Xiao J. Human genes influence the interaction between Streptococcus mutans and host caries susceptibility: a genome-wide association study in children with primary dentition. Int J Oral Sci. 2019;11:19.

75. Yadav K, Prakash S. Dental caries: a microbiological approach. J Clin Infect Dis Pract. 2017;2(1):118.

76. Forssten SD, Björklund M, Ouwehand AC. Streptococcus mutans, caries and simulation models. Nutrients. 2010;2(3):290-8.

77. Ikono R, Vibriani A, Wibowo I, Saputro KE, Muliawan W. Nanochitosan antimicrobial activity against Streptococcus mutans and Candida albicans dual-species biofilms. BMC Res Notes. 2019;12:383. https://doi. org/10.1186/s13104-019-4422-x. 
78. Sims KR, Liu Y, Hwang G, Jung HI, Koo H, Benoit DSW. Enhanced design and formulation of nanoparticles for antibiofilm drug delivery. Nanoscale. 2018;11(1):219-36.

79. Liu Y, Ren Y, Li Y, Su L, Zhang Y, Huang F, et al. Nanocarriers with conjugated antimicrobials to eradicate pathogenic biofilms evaluated in murine in vivo and human ex vivo infection models. Acta Biomater. 2018;79:331-43. https://doi.org/10.1016/j.actbio.2018.08.038.

80. Fiorillo L, Cervino G, Laino L, D'Amico C, Mauceri R, Fikret Tozum T, et al. Porphyromonas gingivalis, periodontal and systemic implications: a systematic review. Dent J (Basel). 2019;7(4):114.

81. Mahmoud MY, Steinbach-rankins JM. Functional assessment of peptide-modified PLGA nanoparticles against oral biofilms in a murine model of periodontitis. J Control Release. 2019;297:3-13. https://doi. org/10.1016/j.jconrel.2019.01.036.

82. Toledano-osorio M, Babu JP, Osorio R, Medina-castillo AL, Garc F, Toledano M. Modified polymeric nanoparticles exert in vitro antimicrobial activity against oral bacteria. Materials. 2018;11:1013.

83. Fhogartaigh CN, Dance DAB. Bacterial gastroenteritis. Gastrointestinal Infect. 2013;41(12):693-9.

84. Das S, Angsantikul P, Le C, Bao D, Miyamoto Y, Gao W, et al. Neutralization of cholera toxin with nanoparticle decoys for treatment of cholera. PLoS Negl Trop Dis. 2018;12(2):e0006266.

85. Taha-Abdelaziz K, Yitbarek A, Alkie TN, Hodgins DC. PLGA-encapsulated CpG ODN and Campylobacter jejuni lysate modulate cecal microbiota composition in broiler chickens experimentally challenged with. Sci Rep. 2018;8:12076. https://doi.org/10.1038/s41598-018-30510-w.

86. Shirota H, Klinman D. CpG oligodeoxynucleotides as adjuvants for clinical use. In: Immunopotentiators in modern vaccines, 2nd ed. Elsevier; 2017. p. 163-98. 10.1016/B978-0-12-804019-5.00009-8

87. Kurtz JR, Goggins JA, McLachlan JB. Salmonella infection: interplay between the bacteria and host immune system. Immunol Lett. 2017;190:42-50

88. Wotzka SY, Nguyen BD, Hardt W-D. Salmonella typhimurium diarrhea reveals basic principles of enteropathogen infection and diseasepromoted DNA exchange. Cell Host Microbe. 2017;21(4):443-54.

89. Rishi P, Bhogal A, Arora S, Pandey SK, Verma I, Pal I. Improved oral therapeutic potential of nanoencapsulated cryptdin formulation against Salmonella infection. Eur J Pharm Sci. 2015;72:27-33. https:// doi.org/10.1016/j.ejps.2015.02.014.

90. Gravina AG, Zagari RM, De MC, Romano L, Loguercio C, Romano M. Helicobacter pylori and extragastric diseases: a review. World J Gastroenterol. 2018;24(29):3204-21.

91. Angsantikul P, Thamphiwatana S, Zhang Q, Spiekermann K, Zhuang J, Fang RH, et al. Coating nanoparticles with gastric epithelial cell membrane for targeted antibiotic delivery against Helicobacter pylori infection. Adv Therap. 2018;1 (2):1800016.

92. Boyanova L, Hadzhiyski P, Kandilarov N, Markovska R, Mitov I. Multidrug resistance in Helicobacter pylori: current state and future directions. Expert Rev Clin Pharmacol. 2019;12(9):909-15.

93. Løvmo SD, Tobias M, Repnik U, Olaf E, Wyn G, Paul J. Translocation of nanoparticles and Mycobacterium marinum across the intestinal epithelium in zebrafish and the role of the mucosal immune system. Dev Comp Immunol. 2017:67:508-18.

94. Mistik S, Uludag A, Kartal D, Cinar SL. Bacterial skin infections: epidemiology and latest research. TJFMPC. 2015;9(2):65-74.

95. Hasan N, Cao J, Lee J, Hlaing SP, Oshi MA, Naeem M, et al. Bacteriatargeted clindamycin loaded polymeric nanoparticles: effect of surface charge on nanoparticle adhesion to MRSA, antibacterial activity, and wound healing. Pharmaceutics. 2019;11:236.

96. Han C, Goodwine J, Romero N, Steck KS, Sauer K. Enzyme-encapsulating polymeric nanoparticles: a potential adjunctive therapy in Pseudomonas aeruginosa biofilm-associated infection treatment. Colloids Surf B. 2019;184:110512. https://doi.org/10.1016/j.colsurfb.2019.110512.

97. Goodwine J, Gil J, Doiron A, Valdes J, Solis M, Higa A, et al. Pyruvate-depleting conditions induce biofilm dispersion and enhance the efficacy of antibiotics in killing biofilms in vitro and in vivo. Sci Rep. 2019;9:3763.

98. Ong TH, Chitra E, Ramamurthy S, Chong C, Ling S, Ambu SP, et al. Cationic chitosan-propolis nanoparticles alter the zeta potential of $S$. epidermidis, inhibit biofilm formation by modulating gene expression and exhibit synergism with antibiotics. PLoS ONE. 2019;14(2):e213079.

99. Takahashi C, Hattori Y, Yagi S, Murai T, Takai C, Ogawa N, et al. Optimization of ionic liquid-incorporated PLGA nanoparticles for treatment of biofilm infections NPs suspension Centrifuge. Mater Sci Eng C. 2019;97:78-83. https://doi.org/10.1016/j.msec.2018.11.079.

100. Medina M, Castillo-Pino E. An introduction to the epidemiology and burden of urinary tract infections. Ther Adv Urol. 2019;11:3-7.

101. Tandogdu Z, Wagenlehner FME. Global epidemiology of urinary tract infections. Curr Opin Infect Dis. 2016;29(1):73-9.

102. Lüthje $P$, Brauner A. Virulence factors of uropathogenic E. coli and their interaction with the host. Adv Microb Physiol. 2014;65:337-72.

103. Vila J, Sáez-López E, Johnson R, Römling U, Dobrindt U, Cantón R, et al. Escherichia coli: an old friend with new tidings. FEMS Microbiol Rev. 2016;40(4):437-63.

104. Ashmore DA, Chaudhari A, Barlow B, Barlow B, Harper T, Vig K, et al. Evaluation of E. coli inhibition by plain and polymer-coated silver nanoparticles. Rev Inst Med Trop São Paulo. 2018;60:e8.

105. Alfaro-viquez E, Esquivel-alvarado D, Madrigal-carballo S, Krueger CG, Reed JD. Proanthocyanidin-chitosan composite nanoparticles prevent bacterial invasion and colonization of gut epithelial cells by extra-intestinal pathogenic Escherichia coli. Int J Biol Macromol. 2019;135:630-6. https://doi.org/10.1016/j.ijbiomac.2019.04.170.

106. Kumar GV, Su C-H, Velusamy P. Surface immobilization of kanamycinchitosan nanoparticles on polyurethane ureteral stents to prevent bacterial adhesion. Biofouling. 2016;32(8):861-70.

107. Zhang A, Mu H, Zhang W, Cui G, Zhu J, Duan J. Chitosan coupling makes microbial biofilms susceptible to antibiotics. Sci Rep. 2013;3:3364

108. Liu S, Qiao S, Li L, Qi G, Lin Y. Surface charge-conversion polymeric nanoparticles for photodynamic treatment of urinary tract bacterial infections. Nanotechnology. 2015;26:495602.

109. Bračič M, Fras-Zemljič L, Pérez L, Kogej K, Stana-Kleinschek K, Kargl R, et al. Protein-repellent and antimicrobial nanoparticle coatings from hyaluronic acid and a lysine-derived biocompatible surfactant. J Mater Chem B. 2017;5:3888-97.

110. Dayyoub E, Frant M, Reddy S, Liefeith K. Antibacterial and anti-encrustation biodegradable polymer coating for urinary catheter. Int J Pharm. 2017;531(1):205-14. https://doi.org/10.1016/j.jpharm.2017.08.072.

111. Maruthupandy M, Rajivgandhi G, Kadaikunnan S, Khaled JM, Jun-li W, Alanzi KF. Anti-biofilm investigation of graphene / chitosan nanocomposites against biofilm producing P. aeruginosa and K. pneumoniae. Carbohydr Polym. 2020;230:115646.

112. Giovane R, Lavender P. Central nervous system infections. Prim Care. 2018:45(3):505-18.

113. Brouwer MC, Tunkel AR, Van De BD. Epidemiology, diagnosis, and antimicrobial treatment of acute bacterial meningitis. Clin Microbiol Rev. 2010;23(3):467-92.

114. Debiasi RL, Tyler KL. Molecular methods for diagnosis of viral encephalitis. Clin Microbiol Rev. 2004;17(4):903-25.

115. Robertson FC, Lepard JR, Mekary RA, Davis MC, Yunusa I, Gormley WB, et al. Epidemiology of central nervous system infectious diseases: a meta-analysis and systematic review with implications for neurosurgeons worldwide. J Neurosurg. 2019;130:1107-26.

116. GBD. Global, regional, and national age-sex specific all-cause and cause-specific mortality for 240 causes of death, 1990-2013: a systematic analysis for the Global Burden of Disease Study 2013. Lancet. 2014;385(9963):117-71.

117. Cano A, Sánchez-López E, Ettcheto M, López-Machado A, Espina M, Souto EB, et al. Current advances in the development of novel polymeric nanoparticles for the treatment of neurodegenerative diseases. Nanomedicine (London). 2020;15(12):1239-61.

118. Christodoulides M, Heckels J. Novel approaches to Neisseria meningitidis vaccine design. Pathog Dis. 2017;75(3):1-16.

119. Gala RP, Souza MD, Zughaier SM. Evaluation of various adjuvant nanoparticulate formulations for meningococcal capsular polysaccharidebased vaccine. Vaccine. 2016;34(28):3260-7. 
120. Long Y, Li Z, Bi Q, Deng C, Chen Z, Bhattachayya S, et al. Novel polymeric nanoparticles targeting the lipopolysaccharides of Pseudomonas aeruginosa. Int J Pharm. 2016;502:232-41.

121. Shah SS, Gloor P, Gallagher PG. Bacteremia, meningitis, and brain abscesses in a hospitalized infant: complications of Pseudomonas aeruginosa conjunctivitis. J Perinatol. 1999;19:462-5.

122. Hong W, Zhang Z, Liu L, Zhao Y, Zhang D, Liu M. Brain-targeted delivery of PEGylated nano-bacitracin A against Penicillin-sensitive and -resistant Pneumococcal meningitis: formulated with RVG 29 and Pluronic V P85 unimers. Drug Deliv. 2018;25(1):1-12.

\section{Publisher's Note}

Springer Nature remains neutral with regard to jurisdictional claims in published maps and institutional affiliations.
Ready to submit your research? Choose BMC and benefit from:

- fast, convenient online submission

- thorough peer review by experienced researchers in your field

- rapid publication on acceptance

- support for research data, including large and complex data types

- gold Open Access which fosters wider collaboration and increased citations

- maximum visibility for your research: over $100 \mathrm{M}$ website views per year

At BMC, research is always in progress.

Learn more biomedcentral.com/submissions 